\title{
PROSPECT THEORY AND UTILITY THEORY: TEMPORARY VERSUS PERMANENT ATTITUDE TOWARDS RISK
}

\author{
Haim Levy ${ }^{*}$ and Zvi Wiener ${ }^{*}$
}

October 2002

\begin{abstract}
Prospect Theory (PT), which relies on subjects' behavior as observed in laboratory experiments contradicts the behavior predicted by the Expected Utility (EU) paradigm. In this study, we introduce the concept of Temporary Attitude Towards Risk (TATR) and Permanent Attitude Towards Risk (PATR). Using these concepts, we build a model that merges both the PT and the EU paradigms. The TATR and PATR concepts explain recent experimental findings and the observed stock price overreaction. We relate the properties of PT to some well-known financial and economic results. We show that a positive risk premium with decreasing absolute risk aversion (DARA) can be consistent with the S-shaped value function used in PT. Finally, we introduce the Prospect Stochastic Dominance (PSD) rule for partial ordering of uncertain prospects for all S-shaped value functions.
\end{abstract}

JEL Classification Codes: D81, G0

Keywords: Utility Theory, Prospect Theory, value function, risk attitude

* School of Business, The Hebrew University of Jerusalem, Jerusalem, Israel.

Tel: 972-2-588-3101, e-mail: mshlevy@mscc.huji.ac.il_ (corresponding author)

Tel: 972-2-588-3049, e-mail: mswiener@mscc.huji.ac.il

The authors wish to thank B. Barlev, A. Cohen, M. Levy, Z. Shapira, and S. Yitzhaki for their helpful comments. Financial support from the Krueger Center of Finance is appreciated. 


\section{PROSPECT THEORY AND UTILITY THEORY: TEMPORARY VERSUS PERMANENT ATTITUDE TOWARDS RISK}

Theories of decision making under uncertainty and, in particular, portfolio selection, assume (explicitly or implicitly) expected utility (EU) maximization. Yet, EU is criticized on several grounds. Probably the most well known criticism was made by the French economist, Maurice Allais $(1953,1988,1990)$, who showed that preferences are non-linear. According to Allais, an increase in the probability of receiving an amount w from .99 to 1.00 has more impact on individuals than an increase in the probability of receiving $\mathrm{w}$ from .10 to .11 . This contradicts the expected utility theory that predicts an equal increase, of $0.01 \mathrm{U}(\mathrm{w})$ in both cases, $\mathrm{U}$ being the utility function.

Markowitz (1952) also pointed out possible contradictions to the expected utility theory as early as 1952. Markowitz proposes a utility function that explains gambling and insurance which differs significantly from Friedman and Savage's (1948) utility function. To the best of our knowledge, Markowitz was the first to raise a few important issues, later on confirmed by experimental studies. First, he claims that not only total wealth but also change of wealth may be a factor in the decision making process, and second, that "temporary" changes in the utility function might take place and therefore a distinction should be made between "customary" wealth and present wealth. Moreover, he also suggested that the inflection point temporarily "travels" along the utility function:

"So far I have assumed that the second inflection corresponds to present wealth. There are reasons for believing that this is not always the case. For example, suppose that our hypothetical stranger, rather than offering to give you $\$ X$ or a chance of $\$ Y$, had instead first given you the $\$ X$ and then had offered you a fair bet which if lost would cost you $-\$ X$ and if won 
would net you $\$(Y-X)$. These two situations are essentially the same, and it is plausible to expect the chooser to act in the same manner in both situations. But this will not always be the implication of our hypotheses if we insist that the second inflection point always corresponds to present wealth. We can resolve this dilemma by assuming that in the case of recent windfall gains or losses, the second inflection point may temporarily deviate from present wealth. The level of wealth which corresponds to the second inflection point will be called "customary wealth." (See Markowitz (1952), p. 154-155 and also Mosteller and Nogee (1951)).

In a very well cited article Kahneman and Tversky (1979) suggested a new model which competes with the expected utility paradigm. They conducted a series of experiments showing that subjects make decisions based on change in wealth rather than total wealth; and that subjects tend to subjectively overweight low probabilities. The combination of these two factors (together with a few more ingredients to be spelled out later in the paper) served to create a new explanatory framework of investor's behavior which was coined Prospect Theory (PT) by Kahneman and Tversky. PT competes with the von Neumann and Morgenstern (NM) expected utility theory. It is based on the experimental results that do not confirm with the expected utility theory. In a further development Tversky and Kahneman (T\&K (1992)) propose Cumulative Prospect Theory (CPT) which preserves the main ingredients of PT without violating first degree stochastic dominance. The main difference between PT and CPT is that the subjective decision weights are assigned to the cumulative probabilities rather than to the probabilities themselves. ${ }^{1}$

Before we turn to the objectives of our paper let us summarize the main findings of PT:

1) Most subjects violate expected utility exactly as shown by Allais.

2) Subjects are commonly concerned with changes in wealth rather than total wealth, in contradiction to the expected utility paradigm.

3) Subjects act to maximize the expected value function $V_{w}(x)$, which is S-shaped, 
(concave for gains - risk aversion, and convex for losses - risk seeking). The value function is steeper for losses than it is for gains.

4) Subjective decision weights are assigned to probability and are employed in calculating expectations (alternatively the cumulative probability is subjectively changed).

Our model is motivated by the hypothesis that it takes time to investors to adjust to changes, in particular in their wealth. This hypothesis is not new. For example, Rabin (1998) asserts:

"Overwhelming evidence shows that humans are often more sensitive to how their current situation differs from some reference level than to the absolute characteristics of the situation (Harry Helson 1964). For instance, the same temperature that feels cold when we are adapted to hot temperatures may appear hot when we are adapted to cold temperatures. Understanding that people are often more sensitive to changes than to absolute levels suggests that we ought incorporate into utility analysis such factors as habitual levels of consumption. Instead of utility at time $t$ depending solely on present consumption, $c_{t}$, it may also depend on a "reference level," $r_{t}$, determined by factors like past consumption or expectations of future consumption. Hence, instead of a utility function of the form $u_{t}\left(c_{t}\right)$, utility should be written in a more general form, $u_{t}\left(r_{t} ; c_{t}\right)$.

The objective of this paper is threefold:

a. First we integrate prospect theory with expected utility theory. Based on Markowitz's hypothesis and the experimental findings that change of wealth, $\mathrm{x}$ and the initial wealth $\mathrm{w}$, are important factors in the decision making process, we define a two-dimensional utility function $\mathrm{U}(\mathrm{w}, \mathrm{x})$ (without restricting ourselves to a particular shape apart from the condition that the marginal utilities of $\mathrm{w}$ and of $\mathrm{x}$ 
are positive). Thus we treat $\mathrm{w}$ and $\mathrm{x}$ as two different commodities which generally can not be combined. This is very similar to formulation given by Kihlstrom and Mirman (1974, 1981), Levhari, Paroush and Peleg (1975), Levy and Paroush (1974), and Levy (1976), where the utility function is defined on many commodities. The experimental findings reveal that $\mathrm{w}$ and $\mathrm{x}$ can not be combined, at least not in a short run, because the investment decisions of a person who had wealth of $\mathrm{w}=\$ 90,000$ and just suddenly won another $\mathrm{x}=\$ 10,000$ is different from the investment decisions of a person who's wealth was $\$ 100,000$ and did not change. Recall that if $\mathrm{U}(\mathrm{w}, \mathrm{x})=\mathrm{U}(\mathrm{w}+\mathrm{x})$ we come back to the classic onedimensional EU utility function. We focus in the paper in particular on another specific $\operatorname{case}^{2} \mathrm{U}(\mathrm{w}, \mathrm{x})=\mathrm{U}(\mathrm{w})+\mathrm{V}_{\mathrm{w}}(\mathrm{x})$, which corresponds to the prospect theory framework. Here $\mathrm{w}$ and $\mathrm{x}$ are not combined, and the value function $\mathrm{V}_{\mathrm{w}}(\mathrm{x})$ travels along the utility function $\mathrm{U}(\mathrm{w})$. We emphasize that not only the inflection point travels (see Markowitz (1952)), but also the value function may change shape as w changes. In this framework we decompose $\mathrm{U}(\mathrm{w}, \mathrm{x})$ to its two major components one (V) responsible for short run and sudden or unexpected effects, another (U) responsible for the long run effects. To be more specific, the decision making based on changes in wealth reflects temporary attitude towards risk (TATR), whereas decision making based on total wealth reflects permanent attitude towards risk (PATR). However, note that even temporary attitude towards risk may depend on wealth (w); hence, we have a value function with two arguments which can be written as $\mathrm{V}_{\mathrm{w}}(\mathrm{x})$, where the changes in wealth $\mathrm{x}$ are emphasized. If an investor holds $\mathrm{w}$ and faces a change of wealth $\mathrm{x}$, he ends up with $\mathrm{w}_{1}=\mathrm{w}+\mathrm{x}$. Yet, the utility from this new wealth $\mathrm{w}_{1}$ is path-time dependent: It is path-dependent because the 
way $\mathrm{w}_{1}$ was achieved affects utility and it is path-time dependent because the time affects utility. To be more specific in the long run the path by which the wealth was achieved becomes less important and only the level of wealth determines utility. This structure of preference confirms experimental findings. Moreover, we show that the combination of TATR and PATR can explain some of the experimental results and, in particular, the results obtained by Thaler and Johnson (1990) and the well-known phenomenon of short-term overreaction of stock prices. 3

b. It is well documented in the literature that the risk premium is (generally) positive. Moreover, Pratt (1964) and Arrow (1965) show that the risk premium decreases with wealth (DARA-decreasing absolute risk aversion). We analyze the concept of risk premium in the PT framework and show that positive risk premium is consistent with the experimental results asserting that the convex segment of the value function is steeper than the concave segment. From the fact that the risk premium decreases with wealth, we conclude that under certain conditions, the value function $\mathrm{V}_{\mathrm{w}}(\mathrm{x})$ rotates about $\mathrm{x}=0$, in a clockwise direction as $\mathrm{w}$ increases. By the same argument also the reversed S-shaped utility function suggested by Markowitz (1952) is consistent with the existence of positive risk premium (because Markowitz requires that the concave part is steeper then the convex part.

c. Assuming that the value function is an S-shaped function as implied by PT, we establish a stochastic dominance rule, called PSD (Prospect Stochastic Dominance), specifying the conditions for dominance of one prospect over another for all S-shaped value functions $\mathrm{Vw}(\mathrm{x})$. Finally, in this paper, we focus 
on the relationship between the value function and the utility function, and not on probabilities and weights and, therefore, we do not distinguish between PT and CPT, and simply refer to $\mathrm{PT}^{4}$

\section{Temporary and Permanent Attitude Towards Risk}

The following notations will be used throughout the paper:

w - initial wealth

$\mathrm{x}-\quad$ change in wealth (in absolute terms)

$f(x)$ - the density function of $x$ with a cumulative distribution $F(x)$.

$\mathrm{V}_{\mathrm{w}}(\mathrm{x})$ - a value function measuring additional value due to changes in $\mathrm{x}$, with zero as a reference point. Thus, if $x=0, V_{w}(0)=0$. The shape of the function depends on $w$, hence the subscript $w$. This is the value function suggested by K\&T (1979).

$\mathrm{U}(\mathrm{w})$ - the NM utility function. In the rest of the paper, $\mathrm{U}(\mathrm{w})$ is referred to as the utility function.

$\mathrm{U}(\mathrm{w}, \mathrm{x})-$ the two dimensional utility function, and generally $\mathrm{U}(\mathrm{w}, \mathrm{x}) \neq \mathrm{U}(\mathrm{w}+\mathrm{x})$ because in the short term in a sudden and unexpected change in wealth, $w$ is different from its long-term and expected effect. However when $\mathrm{w}$ and $\mathrm{x}$ can be added to a total sum we are back in the one-dimensional NM utility paradigm. In this study we focus on the following specific form of the two-dimensional utility function,

$$
\mathrm{U}(\mathrm{w}, \mathrm{x})=\mathrm{U}(\mathrm{w})+\mathrm{V}_{\mathrm{w}}(\mathrm{x})
$$

where $\mathrm{U}(\mathrm{w})$ is the classic NM utility function which can take any (reasonable) form, see Figures1 and 2.

(Insert Figures 1a and 1b here) 
As explained in the introduction $\mathrm{U}(\mathrm{w}, \mathrm{x})$ is a path-time-dependent utility function. We adopt the path-time-dependent utility function because it confirms with most experimental findings and in particular with the S-shaped value function suggested by Kahneman and Tversky (1979).

Let us elaborate on the "surprise effect" of $\mathrm{x}$, and its importance for the two-dimensional utility function. Suppose that you have wealth of $w$ and you hold in addition $n$ units of a longterm government bond with market value $\mathrm{nP}_{\mathrm{B}}$. You know and expect market fluctuations in $\mathrm{P}_{\mathrm{B}}$ due to possible changes in interest rate. Suppose that you expect possible changes in interest rate in the range $\pm 0.25 \%$ and therefore expect the corresponding fluctuations in $\mathrm{P}_{\mathrm{B}}$. If there are no changes in interest rate, then you expect $\mathrm{P}_{\mathrm{B}}$ to grow over time due to the continuous accumulated interest. Thus, with no surprises the utility is $\mathrm{U}\left(\mathrm{w}+\mathrm{nP} \mathrm{P}_{\mathrm{B}}\right)$. Due to September 2001 terrorist attack on the U.S. and its impact on the market, the Federal Reserve Bank cuts substantially the interest rate in a very short period of time. In such a case, a holder of long-term government bonds has an unexpected gain, because the sharp cut in interest rates as well as the terrorist attack were a complete surprise to the investors. In such a case, the investor's utility is $\mathrm{U}\left(\mathrm{w}+\mathrm{nP} \mathrm{P}_{\mathrm{B}}, \mathrm{n} \Delta \mathrm{P}_{\mathrm{B}}\right)$, where $\Delta \mathrm{P}_{\mathrm{B}}$ is the unexpected gain due to the sharp unexpected cut in interest rates. Similarly, the holder of United Airlines stocks has a wealth of $\left(\mathrm{w}+\mathrm{P}_{0}\right)$ and utility of $\mathrm{U}\left(\mathrm{w}+\mathrm{P}_{0}\right)$ where $\mathrm{P}_{0}$ is the value of the stocks of United Airlines. As a result of the terrorist attacks the value $\mathrm{P}_{0}$ dropped by about $40 \%$ in one day. Because this was unexpected, the damage in utility terms was much larger than the expected drop of $40 \%$ in $\mathrm{P}_{0}$. Thus, the investor's utility in this case is

$$
\mathrm{U}\left(\mathrm{w}+\mathrm{P}_{0},-0.4 \mathrm{P}_{0}\right)<\mathrm{U}\left(\mathrm{w}+0.6 \mathrm{P}_{0}\right)
$$

Let us go to the other, albeit artificial, example. Suppose that a firm's CEO holds stocks of his company and he is not allowed to sell them in the next five years. He knows that due to insider information accumulated in his firm, bad news will emerge and the stock price will drop 
by about $40 \%$. When the news was released, it indeed dropped by $40 \%$. This one-day drop in stock price is not a surprise to the CEO, hence his utility will be $U(w+0.6 p)$ (where $0.6 p$ is the value of equity after the drop in price). On the other hand, for investors who did not possess the private information, the utility will drop to $\mathrm{U}(\mathrm{w}+\mathrm{p},-0.4 \mathrm{p})$, where for simplicity we assume that utility function, wealth and stocks held by the CEO and the investor are identical. Therefore, the investor is worse off relative to the CEO in utility terms because $U(w+0.6 p)>U(w+p,-0.4 p)$.

In the rest of the paper when we relate to short-run or temporary effect, we implicitly or explicitly mean that it also contains a "surprise" or unexpected effect. If you invest in Treasury Bills and get every week $x=r / 52$ where $r$ is the annual interest rate, though $x$ corresponds to short-run effect, it does not contain a surprise effect and the wealth increases every week by $\mathrm{x}$ and the NM one-dimensional utility function is relevant.

To sum up when an unexpected change occurs we require that for $\mathrm{x}>0$ the following holds:

$$
\begin{aligned}
& \mathrm{U}(\mathrm{w}, 0)<\mathrm{U}(\mathrm{w}-\mathrm{x}, \mathrm{x}) \equiv \mathrm{U}(\mathrm{w}-\mathrm{x})+\mathrm{V}_{\mathrm{w}-\mathrm{x}}(\mathrm{x}) \\
& \mathrm{U}(\mathrm{w}, 0)>\mathrm{U}(\mathrm{w}+\mathrm{x},-\mathrm{x}) \equiv \mathrm{U}(\mathrm{w}+\mathrm{x})+\mathrm{V}_{\mathrm{w}+\mathrm{x}}(-\mathrm{x}),
\end{aligned}
$$

where $\mathrm{x}$ is short-run surprise change of wealth.

Our specific two-dimensional utility function is also time dependent, because in the long run both $\mathrm{U}(\mathrm{w}-\mathrm{x}, \mathrm{x})$ and $\mathrm{U}(\mathrm{w}+\mathrm{x},-\mathrm{x})$ become closer to each other and approach $\mathrm{U}(\mathrm{w}, 0)=\mathrm{U}(\mathrm{w})$. The experimental studies do not provide a unique answer of how long does it take to converge to the NM utility.

This approach allows us to incorporate the Prospect Theory (PT) as a specific case of two-dimensional utility function. PT emphasizes changes of wealth and not total wealth. However, PT does not ignore initial wealth. K\&T claim that the initial wealth serves as a reference point ${ }^{5}$ :

"The emphasis on changes as the carriers of value should not be taken to imply that the 
value of a particular change is independent of initial position. Strictly speaking, value should be treated as a function of two arguments: the asset position that serves as a reference point, and the magnitude of the change (positive or negative) from the reference point," (see K\&T, 1979, p. 277).

K\&T realize that initial wealth affects the value function but they do not investigate its effects further, nor do they address the relationship between value function, utility function and wealth. Based on experimental results, K\&T claim that the value function V is S-shaped with $\mathrm{V}^{\prime}>0$ for all $\mathrm{x} \neq 0$, and $\mathrm{V}^{\prime \prime}>0$ for $\mathrm{x}<0$ and $\mathrm{V}^{\prime \prime}<0$ for $\mathrm{x}>0$ (in this paper, prime denotes the derivative with respect to a change in wealth, $\mathrm{x}$, if no confusion arises we omit the subscript $\mathrm{w}$ ).

Markowitz (1952) suggests a reversed S-shaped form for the utility function with and $\mathrm{V}^{\prime \prime}<0$ for $\mathrm{x}<0$ and $\mathrm{V}^{\prime \prime}>0$ for $\mathrm{x}>0$. Most of our analysis refers to K\&T S-shaped function but as we shall see below the stock overreaction phenomena can be better explained with Markowitz's reversed S-shaped function.

Figure $1 \mathrm{a}$ demonstrates $\mathrm{K} \& \mathrm{~T}$ value function with $\mathrm{w}=0$ as a reference point. Figure $1 \mathrm{~b}$ shows $\mathrm{NM}$ utility function of wealth $\mathrm{U}(\mathrm{w})$ and two utility functions $\mathrm{U}\left(\mathrm{w}_{1}, \mathrm{x}\right)$ and $\mathrm{U}\left(\mathrm{w}_{2}, \mathrm{x}\right)$, i.e. two-dimensional utility functions which can be interpreted also as two value functions for two levels of wealth $\mathrm{w}_{1}$ and $\mathrm{w}_{2}$. Experiments show that in the short run the subjects make decisions due to unexpected change in wealth based on $\mathrm{U}(\mathrm{w}, \mathrm{x})$, namely, according to the Sshaped value function. However, in the long run the utility of the new wealth (resulting from the subject's decisions) approaches the NM utility $\mathrm{U}(\mathrm{w})$. Thus, the utility derived from a given outcome is dynamic over time. The satisfaction from unexpected gain and the sorrow from an unexpected loss decay with time, hence the time-dependent utility function terminology.

Another hypothesis of PT is that subjects behave differently immediately after a loss (or 
gain) than later on, after adjusting to the loss (or gain). Though $\mathrm{K} \& \mathrm{~T}$ do not further analyze the implications of this hypothesis, it seems that the value function $\mathrm{V}_{\mathrm{w}}(\mathrm{x})$ reflects short-term overreaction of subjects to a sudden change in wealth (like winning in a lottery), where overreaction is defined relative to the behavior predicted by the expected utility paradigm. Note that the overreaction includes both adjust of beliefs and risk attitude in face of recent gain or loss. In particular, a sharp overreaction occurs in the case of unexpected losses. After some time period has elapsed (which may vary in length among investors), complete adaptation to the loss is expected. However, if there is incomplete adaptation to the loss, the investor will become a risk seeker, choosing investments which otherwise would be rejected. This short-term overreaction is suggested by $\mathrm{K} \& \mathrm{~T}$ :

"This analysis suggests that a person who has not made peace with his losses is likely to accept gambles that would be unacceptable to him otherwise." (See K\&T, 1979, p. 287).

The model that we suggest in this paper assumes that investors are myopic in that they make investment decisions by the utility function with short-term memory $\mathrm{U}(\mathrm{w}, \mathrm{x})$. This has a direct impact on short-term price changes of risky assets, to be elaborated later on in the paper.

Figure 2 illustrates the two-dimensional utility function $\mathrm{U}(\mathrm{w}, \mathrm{x})$. Here we draw it in line of equation (1), thus we have the specific additive shape of $U(w, x)$. Note that for a given $x$, when $\mathrm{w}$ changes, utility is always concave, and for any given $\mathrm{w}$ the function $\mathrm{U}(\mathrm{w}, \mathrm{x})$ is $\mathrm{S}$-shaped in $\mathrm{x}$.

\section{(Insert Figure 2 here)}

Using the relationship, $\mathrm{U}(\mathrm{w}, \mathrm{x})=\mathrm{U}(\mathrm{w})+\mathrm{V}_{\mathrm{w}}(\mathrm{x})$, Figure 2 illustrates the shape of the pathdependent utility function $\mathrm{U}(\mathrm{w}, \mathrm{x})$, and the relationship between TATR and PATR. The TATR is measured along the vertical axis $\mathrm{U}(\mathrm{w}, \mathrm{x})$ for a given $\mathrm{w}$ for various values $\mathrm{x}$. For example, for $\mathrm{w}=$ 
50 we obtain an S-shaped curve with $\frac{\partial}{\partial x} U(w, x)>0$ for all $\mathrm{x} \neq 0$ and $\frac{\partial^{2}}{\partial x^{2}} U(w, x)<0$ for $\mathrm{x}>0$ and $\frac{\partial^{2}}{\partial x^{2}} U(w, x)>0$ for $\mathrm{x}<0 .{ }^{6}$ The slope of the S-shaped value function changes with $\mathrm{w}$, but it remains S-shaped. This can be clearly seen in Figure 2 by comparing the S-shaped functions corresponding to low and high values of w. In Figure 2, $\mathrm{U}(\mathrm{w}, \mathrm{x})$ is assumed to be concave in $\mathrm{w}$ (for a fixed $\mathrm{x}$ ). Similar curves are drawn for various values of $\mathrm{x}$ which are held constant along each curve, when w changes. Facing an uncertain investment, investors will make decisions by $\mathrm{U}(\mathrm{w}, \mathrm{x})$, based on two variables. Thus, the surface of Figure 2 can be employed to measure the investor's TATR for various reference points $\mathrm{w}$, and for various random variables $\mathrm{x}$. The curves along a given $\mathrm{x}$ simply measure the change in the function $\mathrm{U}(\mathrm{w}, \mathrm{x})$ when $\mathrm{w}$ changes (and $\mathrm{x}$ is held constant $)$. Thus, $\left.\mathrm{U}(\mathrm{w}, \mathrm{x})\right|_{\mathrm{x}=\text { const }}$ is similar to the $\mathrm{NM}$ utility function $\mathrm{U}(\mathrm{w}+\mathrm{x})$ where $\mathrm{x}$ is constant and w changes. Obviously, the precise shape of the surface in Figure 2 may vary from one investor to another. The two components, $\mathrm{U}(\mathrm{w})$ and $\mathrm{V}_{\mathrm{w}}(\mathrm{x})$ of $\mathrm{U}(\mathrm{w}, \mathrm{x})$ are important for decision making and both affect the prices of risky assets. The $\mathrm{U}(\mathrm{w})$ part affects the long-run behavior of the prices of risky assets (corresponding to $\mathrm{NM}$ utility function). The $\mathrm{V}_{\mathrm{w}}(\mathrm{x})$ part affects the short-run behavior of prices of risky assets. In section III we develop a dominance decision rule for one prospect over another for all surfaces of the type given in Figure 2.

We show below the relationship between the path-dependent function $\mathrm{U}(\mathrm{w}, \mathrm{x})$, the overreaction effect and the NM utility function, $\mathrm{U}(\mathrm{x})$. However, before we present our analysis, let us discuss briefly an important experimental result that directly addresses the influence of time on attitude towards risk (TATR and PATR). A series of experiments conducted by Thaler and Johnson (1990) produced several interesting results. Of particular importance to our analysis is their experiment involving a two-week gap between payments.

In a series of three experiments Thaler and Johnson asked 65 participants whether they 
prefer two events to occur on the same day or two weeks apart (see Table 2 in their paper).

In the first experiment the events are:

(i) win $\$ 25$ in an office lottery

(ii) win $\$ 50$ in an office lottery

$25 \%$ of participants preferred the two events to occur on the same day; $63 \%$ preferred the events to be two weeks apart; and $12 \%$ were indifferent.

In the second experiment the events are:

(i) receive a letter from the federal income tax authority saying that due to an arithmetical mistake $\$ 100$ must be paid.

(ii) receive a letter from the state income tax authority saying that due to an arithmetical mistake $\$ 50$ must be paid.

$34 \%$ of participants preferred the two events to occur on the same day; $57 \%$ preferred the events to be two weeks apart; and 9\% were indifferent.

In the third experiment the events are:

(i) receive a $\$ 20$ parking ticket

(ii) receive a bill for $\$ 25$ from the registrar because a form was filled in improperly

$17 \%$ of participants preferred the two events to occur on the same day; $75 \%$ preferred the events to be two weeks apart; and 7\% were indifferent.

Summarizing this experiment, Thaler and Johnson state:

"The responses to question 1 reveal that for pairs of gains subjects did respond in the way suggested by the hedonic editing hypothesis. Subjects preferred to spread out the arrival of pleasant events, presumably to help segregate the pleasures experienced. Using the same logic, subjects should prefer to have pairs of losses occur on the same day, to facilitate their integration. However, subjects did not express this preference. Rather, in questions 2 and 3 
subjects indicated that they prefer to experience the losses separately. We have obtained this result repeatedly, for small or large losses, for nonmonetary as well as monetary losses, and for unrelated and related pairs of events. This result is a severe blow to the hedonic editing hypothesis." (See Thaler and Johnson 1990, p.649). These results emphasize that the utility is not only path-dependent it is also time-dependent. Also winning in a lottery or being told that there was a mistake in your income tax calculation constitutes a "suprize" or unexpected change in income. We will show below that the results of the above three experiments can be explained by temporary risk attitude, TATR, (value function) and permanent risk attitude, PATR, (utility function) and the difference between them. Actually, the results of these experiments are in line with our suggestion regarding the relationship between $\mathrm{V}_{\mathrm{w}}(\mathrm{x})$, the path-time-dependent utility function $\mathrm{U}(\mathrm{w}, \mathrm{x})$, and the $\mathrm{NM}$ utility function $\mathrm{U}(\mathrm{w}+\mathrm{x})$, to which we turn next. However, before explaining Thaler and Johnson results in our framework we need first to explain further the TATR and PATR.

The value function $\mathrm{V}_{\mathrm{w}}(\mathrm{x})$ represents the Temporary Attitude Towards Risk (TATR). In particular, if we have wealth $\mathrm{w}_{1}$ and we receive an unexpected income $\mathrm{x}_{1}$, our path-dependent utility is $\mathrm{U}\left(\mathrm{w}_{1}, \mathrm{x}_{1}\right)$, (see point $\mathrm{C}$ in Figure $1 \mathrm{~b}$ ), and if we need to pay (or we lose) an unexpected amount $\mathrm{y}_{1}$, our value function will be $\mathrm{U}\left(\mathrm{w}_{1},-\mathrm{y}_{1}\right)$ (see point $\left.\mathrm{A}\right)$. Namely, in the short run, it hurts both economically and psychologically when the wealth is unexpecedly decreased from $\mathrm{w}_{1}$ to $\mathrm{w}_{1}$ $-\mathrm{y}_{1}$; hence, the value function $\mathrm{U}\left(\mathrm{w}_{1},-\mathrm{y}_{1}\right)$ will be lower than $\mathrm{U}\left(\mathrm{w}_{1}-\mathrm{y}_{1}\right)$. To illustrate, suppose that we invest all our wealth, say $\$ 10,000$, in the stock market and the stock price suddenly goes down by $20 \%$, like in October 1987 or in September 2001. Even though we will have a wealth of $\$ 8,000$ left, the blow of a sudden loss of $\$ 2,000$ will leave us feeling as if we have less than $\$ 8,000$ left. However, this feeling will be temporary. After a short time period (hours, days, or weeks) we adapt to the new wealth; in other words, we will feel that we have $\$ 8,000$ and not less 
(and behave appropriately). This means that we will have "made peace" with our loss (see K\&T, 1979, p.287). Then, after a complete adjustment is achieved, we move to a new value, which coincides with $\mathrm{U}(8,000)$. Thus, the utility is a function of the path the wealth is achieved and the time it takes to adopt to the new wealth.

Thus, when the investor "makes peace" with the changes of wealth, there is a shift from point $\mathrm{A}$ to point $\mathrm{B}$, and from point $\mathrm{C}$ to point $\mathrm{D}$ (in a case of gain), reflecting the Permanent Attitude Towards Risk (PATR). However, decisions are made by the S-shaped function U(w, x) which reflects the investor's view of utility at the time of making the decision. Only after a time period long enough to guarantee a complete adjustment, the investor will adapt to the new wealth position, as indicated by a shift from the path-dependent utility $U(w, x)$ to the $N M$ utility $\mathrm{U}(\mathrm{w}+\mathrm{x})$. Many experiments reveal, that investors make decisions based on $\mathrm{U}(\mathrm{w}, \mathrm{x})$ rather than on utility $\mathrm{U}(\mathrm{w}+\mathrm{x})$. This implies that investors are myopic: they consider short-term values and ignore the effect of the future move back to the utility function $U(w+x)$ which takes place when the overreaction (to loss or gain) subsides. For each decision, the path dependent utility, U(w, x), is employed. After the overreaction to changes of wealth subsides, investors turn back to the base utility function $\mathrm{U}(\mathrm{w}+\mathrm{x})$, ready to make a new myopic decision. For example, if the investor's wealth changes from $\mathrm{w}_{1}$ to $\mathrm{w}_{2}>\mathrm{w}_{1}$ and enough time passes the investor will consider a new investment according to $\mathrm{U}\left(\mathrm{w}_{2}\right)$ but react to unexpected changes in wealth according to the new function $\mathrm{U}\left(\mathrm{w}_{2}, \mathrm{x}\right)$ (see Figure $\left.1 \mathrm{~b}\right)$. Note that $\mathrm{U}\left(\mathrm{w}_{2}, \mathrm{x}\right)$ has the same general S-shape but the slope and higher derivatives may differ, reflecting the fact that $\mathrm{U}(\mathrm{w}, \mathrm{x})$ is a function of $\mathrm{x}$ and $\mathrm{w}$, and not of $\mathrm{x}$ alone.

As mention before, $\mathrm{K} \& \mathrm{~T}$ do not analyze the impact of reference point $\mathrm{w}$ on decisionmaking, but merely state that it affects the decision. We will analyze the effect of the reference point on the shape of the value function. Moreover, as we shall see below, $\mathrm{U}(\mathrm{w}, \mathrm{x})$ and $\mathrm{U}(\mathrm{w}+\mathrm{x})$ 
together can explain stock price overreaction to an unexpected new information, and results of Thaler and Johnson's experiment.

Thus, we argue that there are three important factors in the decision making process:

a) Investors maximize the expected value of a two dimensional path-time-dependent utility function $\mathrm{U}(\mathrm{w}, \mathrm{x})$.

b) Investors are myopic, and when an unexpected change in wealth occurs they ignore the utility that will be obtained after full adjustment to the change in wealth is achieved. Therefore when they are faced with an uncertain prospect an error in the decision making process is made.

c) After enough time elapses the utility $U(w, x)$ becomes equal to the utility value $\mathrm{U}(\mathrm{w}+\mathrm{x})$, reflecting the time dependence.

Using TATR and PATR, let us analyze Thaler and Johnson's results discussed above as well as stock market overreaction.

\section{A. Thaler and Johnson's results.}

Let us focus first on experiments 2 and 3 (see section I above). These two experiments reveal that if, for example, unexpectedly, we have to pay, $\$ 100$ and then, on the same day, we unexpectedly have to pay another $\$ 100$, we may be more unhappy than if we had to pay $\$ 100$ today and another $\$ 100$ in two weeks. According to Thaler and Johnson this result is puzzling. We will show that it can be explained by temporary and permanent attitudes towards risk. To see this, consider Figure 3.

\section{(Insert Figure 3 here)}

If we unexpectedly have to pay, $\$ 200$ in one day, we view ourselves at $U(w,-200)$ (point $\mathrm{C}$ in Figure 3). However, if we pay $\$ 100$ today, we view ourselves at $\mathrm{U}(\mathrm{w},-100)$ (point $\mathrm{K}$ in 
Figure 3). After two weeks, most subjects "make peace" with such a loss, implying that they move to the point corresponding to $\mathrm{U}(\mathrm{w}-100)$ on the permanent utility curve (point $\mathrm{A}$ in Figure 3). The overreaction to the loss is over. Then, the subjects pay an additional $\$ 100$, moving to $\mathrm{U}(\mathrm{w}-100,-100)$, from point $\mathrm{A}$ to $\mathrm{B}$. Because point $\mathrm{B}$ is above point $\mathrm{C}$, subjects will be more unhappy with one payment of $\$ 200$ today rather than with two payments of $\$ 100$ each. This explains the results of experiments 2 and 3 of Thaler and Johnson.

We suspect that the period needed to adjust to the loss varies from one investor to another and that it is also a function of the size of the loss: the larger the loss, presumably the longer the time needed to accept it. In Thaler and Johnson's experiment, for most subjects, two weeks is enough to complete this transition of a relatively small monetary loss; hence, with a two-week separation between payments, they end up at point $\mathrm{B}$, which is above point $\mathrm{C}$.

The above experimental results, which seem to contradict intuition, perfectly fit our temporary and permanent attitude towards risk, or the existence of short-term value functions $\mathrm{V}_{\mathrm{w}}(\mathrm{x})$ and a long-term utility function $\mathrm{U}(\mathrm{w}+\mathrm{x})$.

Let us turn now to the results of experiment of Thaler and Johnson cited above. Most investors are happier receiving two gains separated by two weeks than receiving the sum of the two gains on the same day. Figure 4 explains why this preference also fits our model. To see this, consider two gains of $\$ 100$ each and compare them to one gain of $\$ 200$.

\section{(Insert Figure 4 here)}

Receiving \$200 on one day, the investor moves to $\mathrm{U}(\mathrm{w}, 200)$, corresponds to point $\mathrm{A}$ which is above $\mathrm{B}$ corresponding to $\mathrm{U}(\mathrm{w}+200)$. If only $\$ 100$ is received, we move along the curve $\mathrm{U}(\mathrm{w}, \mathrm{x})$ up to point $\mathrm{D}$. When the overreaction effect is over, we move back to point $\mathrm{E}$ on the utility function. Now, another payment of $\$ 100$ is received, and the investor moves along $\mathrm{U}(\mathrm{w}+100, \mathrm{x})$ up to point $\mathrm{C}$. In cases where $\mathrm{C}$ is above $\mathrm{A}$, two gains of $\$ 100$ two weeks apart are 
better than one gain of $\$ 200$ (this occurs with $63 \%$ of subjects).

Obviously, positions of points $\mathrm{C}$ and $\mathrm{A}$ depend on the slopes of functions $\mathrm{V}$ and $\mathrm{U}$. For some investors, point $\mathrm{C}$ may be below point $\mathrm{A}$. However, if subjects do not adjust completely to the new wealth after the first payment, a fortiori they will prefer the two payments over the one large payment. In such a case, they move from the new reference point, $\mathrm{D}$ to point $\mathrm{C}^{*}$ which is higher than C. Thus, there may be subjects who prefer two separate payments (see experiment of Thaler and Johnson) and adjust to their new wealth within two weeks. For them, point $\mathrm{C}$ is above point A, (as illustrated in Figure 4). For those subjects who do not adjust to their new wealth, point $\mathrm{C}^{*}$ is above point $\mathrm{C}$.

Finally, note that for those investors who prefer one payment and do not overreact to losses and gains, or know that they simply move back in the future to $\mathrm{U}\left(\mathrm{w}^{+} \mathrm{x}\right)$, the value function is identical to the utility function $\mathrm{U}(\mathrm{w}, \mathrm{x})=\mathrm{U}(\mathrm{w}+\mathrm{x})$ and indeed there is no need to represent preferences of those investors by two separate variables if only their sum matters. K\&T show that this is not the usual case and most investors go through two steps in the evaluation of $\mathrm{x}$, implying short-term overreaction. Such short-term overreactions are probably less severe for institutional investors than for individual investors.

\section{B. Stock Price Overreaction}

Event studies are usually employed to measure stock market reaction to new and unexpected information. The information can be of any kind: dividends, earnings, mergers, spinoffs, replacement of a firm's chief executive officer, etc. Stock prices have been found to overreact to unexpected new information, at least in the short run. Therefore, some researchers postulate the "stock market overreaction" hypothesis. It asserts that stock prices temporary swing away from their fundamental values due to short-term optimism or pessimism. ${ }^{7}$ There are several 
explanations to the stock price overreaction. We suggest here an explanation related to the two dimensional utility function $\mathrm{U}(\mathrm{w}, \mathrm{x})$. Thus our explanation rely on the fact that change of wealth rather than the total wealth is relevant:

a. Thaler and Johnson (1990) show that after winning in a gamble, subjects tend to take more risk, i.e. tend to gamble with the "house money". This is consistent with our two-dimensional utility function because this corresponds to the case when the way a current wealth is achieved affects decisions (and not only the total wealth). One can easily explain stock price overreaction or gambling with the house money with the reversed S-shaped function suggested by Markowitz or by our two-dimensional utility function, where the second dimension (gains or losses) corresponds to the house money. To be more specific Markowitz suggests that $\mathrm{V}^{\prime \prime}>0$ for $\mathrm{x}>0$, hence investors become (temporarily) risk-lovers after a recent gain $(x>0)$, and tend to take more risk than they should according to $\mathrm{U}(\mathrm{w}+\mathrm{x})$ (expected utility). The opposite holds for $\mathrm{x}<0$.

b. Stock price overreaction can be explained also with K\&T S-shaped function. However, in this case we need to assume that the risk aversion measure is much lower at the point $(\mathrm{w}, \mathrm{x})$ relative to $(\mathrm{w}+\mathrm{x}, 0)$ without changing the shape of the value function.

Thus, stock market overreaction is expected when change of wealth is more relevant than total wealth, this can be explained in the PT framework with TATR and PATR. The market inefficiency is due to the TATR and PATR, or the difference between short-term and long-term preference. Because investors are myopic (TATR) they make wrong investment decisions. Sophisticated investors who realize the TATR property can use this. Indeed three 
mutual funds named Behavioral Value, Behavioral Growth and Behavioral Long/Short, which implicitly employ the difference between TATR and $\mathrm{PATR}^{8}$ have been recently established. A description of a positive behavioral portfolio theory can be found in Shefrin and Statman (2000).

\section{Risk Premium and Prospect Theory}

In this section we show that the value function with a convex segment steeper than its concave part, as observed in laboratory experiments, is consistent with the observed positive risk premium.

Friedman and Savage (1948) and Markowitz (1952) claim that the risk premium can be negative or positive because utility function has both concave and convex segments. Nevertheless, there is virtually consensus in the financial and economic literature that the risk premium is positive. A firm's cost of capital is larger than the risk-free interest rate indicating risk aversion and a positive risk premium. Similarly, the long-run (1926-2000) average annual rate of return on equity in the U.S. is about $13 \%$ while the average annual rate of return on the riskless asset (Treasury bills) is only about $3.9 \%{ }^{9}$

Arrow (1965) and Pratt (1964) developed a risk premium measure, which is a function of

$-\frac{U^{\prime \prime}}{U^{\prime}}$. Arrow (1965) and others ${ }^{10}$ claim that absolute risk aversion (DARA) decreases with wealth: the larger the wealth, the less premium one is willing to give up to get rid of a given risk. 11

In this section, we analyze the existence of a positive risk premium and DARA in the PT framework. Because, the PT value function is S-shaped, some of its properties differ from the concave-shaped utility function. For example, the risk premium can be positive or negative 
depending on the distribution of the payoff. Because the value function is concave in the positive domain, we can easily conclude that for a prospect with positive outcomes only, there will be a positive risk premium. Similarly for a prospect with negative outcomes only, the risk premium will be negative because the value function is convex.

The interesting question, of course, is "What is the risk premium when an investor can either lose or win?" In other words, what is the risk premium in a realistic case where both positive and negative outcomes are possible. In PT, the S-shaped value function has an inflection point at the reference point w; therefore Arrow's approach to measuring risk premium is not applicable because an S-shaped function is not differentiable at the inflection point. With Pratt's approach, the derivatives are taken at $(w+E \widetilde{x})$, where $U^{\prime}$ and $U^{\prime \prime}$ are defined (if $E \widetilde{\mathbf{X}} \neq 0$ ), and the risk premium can be derived. We confine ourselves to the realistic case where $\mathrm{E} \widetilde{\mathrm{x}}>0$ (for the unrealistic case where $\mathrm{E} \widetilde{\mathrm{X}}<0$ the results are inconclusive).

Theorem 1. Risk aversion in the small: Assume that there is a value function $V_{w}(x)$ with $V_{w}{ }^{\prime}>0$, and $V_{w}{ }^{\prime \prime}<0$ for $x>0$ and $V_{w}{ }^{\prime \prime}>0$ for $x<0$. If the convex segment is steeper than the concave segment (as found by $K \& T$ (1979)), there will be a positive risk premium for all small prospects with positive expected value.

Proof. Using the Taylor expansion of the value function around zero we obtain:

$$
V_{w}(x)=\left\{\begin{array}{ll}
\alpha x+o(x), & \text { if } x \geq 0 \\
\beta x+o(x), & \text { if } x<0
\end{array},\right.
$$

where $\beta>\alpha$ because the convex segment is steeper. Here we use the standard notation of o(x) to denote a function of higher order than $\mathrm{x}$ (for small $\mathrm{x}$ ).

Take a random prospect $\widetilde{\mathrm{x}}$ where all possible outcomes are close to zero (between $\mathrm{a}<0$ and $b>0)$, and there is a positive expected value $E \widetilde{x}=\int_{a}^{b} x f(x) d x>0$ where $f$ is the density 
function of $\widetilde{\mathrm{x}}$. Denote by $\mathrm{e}_{-}$and $\mathrm{e}_{+}$the negative and positive parts of this expectation $e_{-}=\int_{a}^{0} x f(x) d x<0, e_{+}=\int_{0}^{b} x f(x) d x>0$. Note that $\left|e_{-}\right|<\left|e_{+}\right|$because $E \widetilde{x}=e_{-}+e_{+}>0$ by assumption. Then the value of this expected payoff $\mathrm{V}_{w}(\mathrm{E} \tilde{\mathrm{x}})$ will be $\alpha\left(e_{-}+\mathrm{e}_{+}\right)$up to terms of higher order. The expected value function will be:

$$
\mathrm{EV}_{w}(\widetilde{\mathrm{x}})=\int_{\mathrm{a}}^{\mathrm{b}} \mathrm{V}_{w}(\mathrm{x}) \mathrm{f}(\mathrm{x}) \mathrm{dx}=\int_{\mathrm{a}}^{0}(\beta \mathrm{x}+o(x)) \mathrm{f}(\mathrm{x}) \mathrm{dx}+\int_{0}^{\mathrm{b}}(\alpha \mathrm{x}+o(x)) \mathrm{f}(\mathrm{x}) \mathrm{dx}=\beta \mathrm{e}_{-}+\alpha \mathrm{e}_{+}+o(x)
$$

Because $\beta>\alpha$ and $\left|e_{-}\right|<e_{+}$, we conclude that for small enough prospects $E_{w}(\widetilde{x})<V_{w}(E \tilde{x})$ implying positive risk premium in the small. ${ }^{12}$

Actually, the argument can be reversed to support K\&T's observation regarding the steepness of the two segments of the value function: If there is a positive risk premium in the small, then $\beta \geq \alpha$ which implies that the value function is steeper (in the weak sense) for $x<0$ than for $\mathrm{x}>0 .{ }^{13}$ Thus, the existence of a positive risk premium in the small can be taken as further validation of the experimental results of $K \& T$ regarding the shape of the value function $\mathrm{V}_{\mathrm{w}}$.

The risk premium in PT is confined to small prospects; hence, the extension of the results to risk premium "in the large" as performed by Pratt, is impossible. Because the value function $\mathrm{V}$ has a convex segment, and such an extension may imply that the risk premium is negative rather than positive. To show that this theorem cannot be extended for risk premium in the large we use the following example:

Take the following (S-shaped) value function (which is steeper for $\mathrm{x}<0$, than for $\mathrm{x}>0$ ):

$$
V_{w}(x)=\left\{\begin{array}{l}
1-e^{-x}, \text { if } x \geq 0 \\
e^{3 x}-1, \text { if } x<0
\end{array}\right.
$$


This function is drawn in Figure 5a

(Insert Figure 5a here)

Consider the prospect $\left(\mathrm{x}_{1}, \mathrm{p} ; \mathrm{x}_{2},(1-\mathrm{p})\right)=(1,0.7 ;-2,0.3)$ which means a gain of 1 with a probability of 0.7 and a loss of 2 with a probability of 0.3 . In this case, the expected payoff is $0.7-0.6=0.1>0$ and the value of the expected payoff is: $V_{w}(E x)=1-e^{-0.1}=0.0951626$. However, the expected value function will be $\left(1-\mathrm{e}^{-1}\right) 0.7+\left(\mathrm{e}^{-6}-1\right) 0.3=0.143228$. Figure $5 \mathrm{~b}$ shows that at the expected outcome (0.1) point $A$ on the $V_{w}$ function $(0.095)$ is below point $B$ $(0.1432)$ on the straight line connecting two extreme payoffs.

(Insert Figure 5b here)

This example demonstrates the existence of a negative risk premium for a prospect with a positive expected payoff. Note that "in the small", the risk premium is positive even for this function, because we have proved above that the risk premium in the small is positive for $\beta>\alpha$ and $\left|\mathrm{e}_{-}\right|<\mathrm{e}_{+}$which holds true in our example. This implies that $\mathrm{EV}_{w}(\widetilde{\mathrm{x}})<\mathrm{V}_{w}(\mathrm{E} \widetilde{\mathrm{x}})$ for small enough prospects with a positive expected value, which is equivalent to the assumption that a positive risk premium prevails. In the above example, the condition "in the small" is violated, hence, we obtained a negative risk premium "in the large."

\section{Decreasing absolute risk aversion (DARA)}

In order to analyze DARA in the utility theory framework, we investigate the change in $\mathrm{U}^{\prime \prime} / \mathrm{U}^{\prime}$ as $\mathrm{w}$ changes. In PT, the decisions are made by the value function $\mathrm{V}_{\mathrm{w}}(\mathrm{x})$; hence, we have to check the relevant derivatives along $\mathrm{V}_{\mathrm{w}}(\mathrm{x})$ as $\mathrm{w}$ changes.

We introduce below the concept of DARA in PT. To investigate changes in the absolute risk aversion as a function of wealth, we repeat the basic steps from Pratt (1964) for the case where the path-dependent utility function depends on both current wealth and possible change in 
wealth $U(w, x)$. We will show that if there is DARA with $U(w, x)$, there will be DARA with the K\&T value function $\mathrm{V}_{\mathrm{w}}(\mathrm{x})$.

With a path-dependent utility function, the risk premium is defined by $\pi(\mathrm{w}, \widetilde{\mathrm{x}})$ given by,

$$
U(\mathrm{w}, \mathrm{E} \widetilde{\mathrm{x}}-\pi(\mathrm{w}, \widetilde{\mathrm{x}}))=E U(\mathrm{w}, \widetilde{\mathrm{x}})
$$

where $(\mathrm{w}, \mathrm{E} \widetilde{\mathrm{x}}-\pi(\mathrm{w}, \widetilde{\mathrm{x}}))$ is the two-dimensional certainty equivalent.

Using the Taylor expansion around the point $(\mathrm{w}, \mathrm{E} \widetilde{\mathrm{x}})^{14}$ in the second variable, for the right side we obtain:

$$
E U(\mathrm{w}, \widetilde{\mathrm{x}})=U(\mathrm{w}, \mathrm{E} \widetilde{\mathrm{x}})+U_{x}(\mathrm{w}, \mathrm{E} \widetilde{\mathrm{x}}) \mathrm{E}(\widetilde{\mathrm{x}}-\mathrm{E} \widetilde{\mathrm{x}})+\frac{1}{2} U_{x x}(\mathrm{w}, \mathrm{E} \widetilde{\mathrm{x}}) \mathrm{E}(\widetilde{\mathrm{x}}-\mathrm{E} \widetilde{\mathrm{x}})^{2}+o(\widetilde{\mathrm{x}}-\mathrm{E} \widetilde{\mathrm{x}})^{2}
$$

where $U_{x}$ is the first partial derivative of the value function with respect to its second argument and $U_{x x}$ is the second derivative. Following Pratt's procedure, for the left side of equation (2) we can write:

$$
U(\mathrm{w}, \mathrm{E} \widetilde{\mathrm{x}}-\pi(\mathrm{w}, \widetilde{\mathrm{x}}))=U(\mathrm{w}, \mathrm{E} \widetilde{\mathrm{x}})-U_{x}(\mathrm{w}, \mathrm{E} \widetilde{\mathrm{x}}) \pi(\mathrm{w}, \widetilde{\mathrm{x}})+o(\pi(\mathrm{w}, \widetilde{\mathrm{x}}))
$$

Using equations (2), (3) and (4), for the path-dependent utility risk premium $\pi$ we obtain:

$$
\pi(\mathrm{w}, \widetilde{\mathrm{x}})=-\frac{U_{x x}(\mathrm{w}, \mathrm{E} \widetilde{\mathrm{x}})}{U_{x}(\mathrm{w}, \mathrm{E} \widetilde{\mathrm{x}})} \frac{\sigma^{2}}{2}+\mathrm{o}\left(\sigma^{2}\right),
$$

which is very similar to Pratt's definition adjusted to the two-dimensional utility function.

Denoting the risk premium in the utility theory by $\pi$, DARA implies that $\partial \pi / \partial \mathrm{w}<0$ (where w is the investor's wealth). In prospect theory, we have a somewhat different formulation: There is a two-dimensional utility function $\mathrm{U}(\mathrm{w}, \mathrm{x})$ which depends on two arguments, $\mathrm{w}$ and $\mathrm{x}$. The investor makes decisions based on the impact of $\mathrm{x}$; therefore, we look at the derivatives $V_{w}^{\prime}$ and $V_{w}^{\prime \prime}$ with respect to $\mathrm{x}$. These derivatives determine the risk premium. However, to test for the existence of DARA, we need to analyze how these derivatives at point $\mathrm{Ex} \neq 0$ change when $\mathrm{w}$ changes. 
Let $\mathrm{U}_{\mathrm{x}}(\mathrm{w}, \mathrm{x}), \mathrm{U}_{\mathrm{xx}}(\mathrm{w}, \mathrm{x})$ denote the first two derivatives with respect to $\mathrm{x}$. The effect of change in these derivatives as a function of $\mathrm{w}$ can be measured by the mixed derivatives $\mathrm{U}_{\mathrm{xw}}$ and $\mathrm{U}_{\mathrm{xxw}}$ We claim below that any path-dependent utility function of this type with

$-\frac{\partial\left(U_{x x} / U_{x}\right)}{\partial w}<0$ is consistent with DARA in PT. To see this, recall that $U_{x}(\mathrm{w}, \mathrm{x})=\mathrm{V}^{\prime}{ }_{w}(\mathrm{x})$ and $U_{x x}(\mathrm{w}, \mathrm{x})=\mathrm{V}^{\prime \prime}{ }_{w}(x)$. Therefore, Pratt's risk aversion is given by:

$$
\pi \cong-\frac{U_{x x}(\mathrm{w}, \mathrm{E} \widetilde{\mathrm{x}})}{U_{x}(\mathrm{w}, \mathrm{E} \widetilde{\mathrm{x}})} \frac{\sigma^{2}}{2}=-\frac{\mathrm{V}^{\prime \prime}{ }_{w}(\mathrm{E} \widetilde{\mathrm{x}})}{\mathrm{V}^{\prime}{ }_{w}(\mathrm{E} \widetilde{\mathrm{X}})} \frac{\sigma^{2}}{2}
$$

and, if $-\partial\left(U_{x x} / U_{x}\right) / \partial \mathrm{w}<0$, we have the same property for the value function, $\mathrm{V}$, and DARA prevails also with the $K \& T$ value function $\mathrm{V}_{\mathrm{w}}(\mathrm{x})$.

(Insert Figures 6a, 6b here)

Figures $6 \mathrm{a}$ and $6 \mathrm{~b}$ demonstrate the concept of DARA in PT. Figure 6a is given in K\&T framework. We have two S-shaped hypothetical functions for an individual investor, corresponding to different levels of wealth. DARA exists if the derivatives satisfy $-\mathrm{V}_{w_{2}}(\mathrm{E} \widetilde{\mathrm{x}}) / \mathrm{V}_{w_{2}}^{\prime}(\mathrm{E} \widetilde{\mathrm{x}})<-\mathrm{V}^{\prime \prime}{ }_{w_{1}}(\mathrm{E} \widetilde{\mathrm{x}}) / \mathrm{V}_{w_{1}}^{\prime}(\mathrm{E} \widetilde{\mathrm{x}})$ when $\mathrm{w}_{2}>\mathrm{w}_{1}$ (and $\mathrm{w}_{2}$ is close enough to $\left.\mathrm{w}_{1}\right)$. Figure $6 \mathrm{~b}$ demonstrates the same idea with the path-dependent utility function. The same relation should hold for the ratio of the derivatives at points A and B. This differs from the utility theory risk premium when a movement along $\mathrm{U}(\mathrm{w})$ is involved. Actually, here we measure the slope on two value functions corresponding to two wealth levels: hence DARA in PT is expressed by moving from one value function to another.

To demonstrate the DARA with a path-dependent utility, let us take the following function as an example:

$$
U(\mathrm{w}, \mathrm{x})=U(\mathrm{w})+\mathrm{V}\left(\frac{\mathrm{x}}{\mathrm{w}}\right) .
$$


This function has the following desired property: the larger the wealth, the smaller the effect of given change $x$ on the value function. The benefit of $x=1$ (or the loss due to $x=-1$ ) is much smaller for $\mathrm{w}=1,000$ than for $\mathrm{w}=10$.

It is easy to verify that for this function, $\partial \pi / \partial \mathrm{w}<0$ :

$$
\pi(\mathrm{w}, \mathrm{E} \widetilde{\mathrm{x}}) \cong-\frac{U_{x x}(\mathrm{w}, \mathrm{E} \widetilde{\mathrm{x}})}{U_{x}(\mathrm{w}, \mathrm{E} \widetilde{\mathrm{x}})} \frac{\sigma^{2}}{2}=-\frac{\mathrm{V}^{\prime \prime}{ }_{w}(\mathrm{E} \widetilde{\mathrm{x}})}{\mathrm{V}^{\prime}{ }_{w}(\mathrm{E} \widetilde{\mathrm{x}})} \frac{1}{\mathrm{w}} \frac{\sigma^{2}}{2}
$$

This formula clearly shows that the risk premium (its absolute value) decreases when wealth increases. Thus, for this specific function, we have two properties: DARA holds and the value function $V_{w}(x)$ changes in a clockwise directions as w increases (see Figure $6 a$ ).

\section{Prospect Stochastic Dominance (PSD)}

It is very important for the choice by prospect theory not to violate First Degree Stochastic Dominance (FSD) (see K\&T (1979) and T\&K (1992)). Indeed, in CPT (unlike PT), T\&K ensure that the probability weight function is such that if there are two prospects, $\mathrm{F}$ and $\mathrm{G}$, and if F dominates G by FSD, such dominance will be found also in the PT framework. Thus, the transformation of cumulative probability does not violate FSD. In this section, we assume that the utility function is path-dependent $\mathrm{U}(\mathrm{w}, \mathrm{x})$, as before, and that $\mathrm{V}_{\mathrm{w}}(\mathrm{x})$ is an S-shaped value function (see eq. (1)). With no constraints on the relationship between $\mathrm{V}_{\mathrm{w}}(\mathrm{x})$ and $\mathrm{w}$ (as long as it remains S-shaped), we derive the conditions for dominance of $\mathrm{F}$ over $\mathrm{G}$ for all S-shaped value functions. We first assume a $\mathrm{V}_{\mathrm{w}}(\mathrm{x})$ function as advocated by $\mathrm{K} \& \mathrm{~T}$ (see Figure 1a), and then show that the results also hold for $\mathrm{U}(\mathrm{w}, \mathrm{x})$. Under certain conditions, the results also hold for the NM utility function $U(w+x)$. To be more specific, we find a condition for dominance of one prospect over another for all possible surfaces $\mathrm{U}(\mathrm{w}, \mathrm{x})$ given in Figure 2, as long as the S-shaped 
feature is maintained along $\mathrm{x}$ for a constant $\mathrm{w}$.

Like K\&T (1979) let us focus on the value function, assuming first that there are no subjective transformations of probabilities. Suppose that there are two uncertain options with density functions $\mathrm{f}(\mathrm{x})$ and $\mathrm{g}(\mathrm{x})$ and that the corresponding cumulative distribution functions are $\mathrm{F}(\mathrm{x})$ and $\mathrm{G}(\mathrm{x})$, where $\mathrm{x}$ is the change in wealth (gains or losses). Then, by PT, F will be preferred to $\mathrm{G}$ if and only if the following holds:

$$
E_{F} V_{w}(x)=\int V_{w}(x) d F(x) \geq \int V_{w}(x) d G(x)=E_{G} V_{w}(x)
$$

where $\mathrm{V}_{\mathrm{w}}(\mathrm{x})$ is the $\mathrm{K} \& \mathrm{~T}$ value function (S-shaped) whose precise shape depends on current wealth w (see Figure 1a). In the following theorem, we provide necessary and sufficient conditions for preference of $\mathrm{F}$ over $\mathrm{G}$ for all value functions $\mathrm{V}_{\mathrm{w}}(\cdot)$ of this type.

Theorem 2. Let $\mathrm{V}_{\mathrm{w}}(\cdot)$ be an S-shaped value function with $\mathrm{V}^{\prime} \geq 0$, where $\mathrm{V}^{\prime \prime} \leq 0$ for gains and $\mathrm{V}^{\prime \prime} \geq 0$ for losses. Then $\mathrm{F}$ will dominate $\mathrm{G}$ by PSD if and only if for any pair $\mathrm{y}<0<\mathrm{x}$,

$$
\int_{y}^{x}(G(t)-F(t)) d t \geq 0
$$

where $\mathrm{F}$ and $\mathrm{G}$ are the cumulative distribution functions of $\mathrm{f}$ and $\mathrm{g}$, respectively.

Proof. We consider the case in which all possible gains/losses are in a bounded domain [a,b]. ${ }^{15}$

a) Sufficiency:

Define by $\Delta \equiv \mathrm{E}_{\mathrm{F}} \mathrm{V}(\mathrm{x})-\mathrm{E}_{\mathrm{G}} \mathrm{V}(\mathrm{x})$ and assume that $\mathrm{x}$ is always in [a,b]. Then

$$
\Delta=\int_{a}^{b} \mathrm{~V}_{\mathrm{w}}(x) d F(x)-\int_{a}^{b} \mathrm{~V}_{\mathrm{w}}(x) d G(x)=\int_{a}^{b} \mathrm{~V}_{\mathrm{w}}(x) d(F(x)-G(x))
$$

Integrating by parts we obtain:

$$
\Delta=\left.\mathrm{V}_{\mathrm{w}}(\mathrm{x})[\mathrm{F}(\mathrm{x})-\mathrm{G}(\mathrm{x})]\right|_{\mathrm{a}} ^{\mathrm{b}}-\int_{\mathrm{a}}^{\mathrm{b}}(\mathrm{F}(\mathrm{x})-\mathrm{G}(\mathrm{x})) \mathrm{V}^{\prime}{ }_{\mathrm{w}}(\mathrm{x}) \mathrm{dx}
$$


Because $a$ and $b$ define the range of $x$, we have $F(b)=G(b)=1$ and $F(a)=G(a)=0$.

Thus, the first term is equal to zero and we are left with:

$$
\Delta=\int_{a}^{b}(G(x)-F(x)) V^{\prime}{ }_{w}(x) d x=\int_{a}^{0}(G(x)-F(x)) V^{\prime}{ }_{w}(x) d x+\int_{0}^{b}(G(x)-F(x)) V_{w}^{\prime}(x) d x
$$

Integrating (10) by parts once again, each of the above two terms on the right-hand side of eq. (10) yields:

$$
\begin{aligned}
& \Delta=\left.\mathrm{V}^{\prime}{ }_{w}(\mathrm{x}) \int_{\mathrm{a}}^{\mathrm{x}}(\mathrm{G}(\mathrm{t})-\mathrm{F}(\mathrm{t})) \mathrm{dt}\right|_{a} ^{0}-\int_{\mathrm{a}}^{0} \mathrm{~V}^{\prime \prime}{ }_{w}(x) \int_{\mathrm{a}}^{\mathrm{x}}(\mathrm{G}(\mathrm{t})-\mathrm{F}(\mathrm{t})) \mathrm{dtdx} \\
& +\left.\mathrm{V}^{\prime}{ }_{w}(\mathrm{x}) \int_{0}^{\mathrm{x}}(\mathrm{G}(\mathrm{t})-\mathrm{F}(\mathrm{t})) \mathrm{dt}\right|_{0} ^{b}-\int_{0}^{b} \mathrm{~V}^{\prime \prime}{ }_{w}(x) \int_{o}^{\mathrm{x}}(\mathrm{G}(\mathrm{t})-\mathrm{F}(\mathrm{t})) \mathrm{dtdx} .
\end{aligned}
$$

Or,

$$
\begin{aligned}
& \Delta=\mathrm{V}^{\prime}{ }_{w}(0) \int_{\mathrm{a}}^{0}[\mathrm{G}(\mathrm{t})-\mathrm{F}(\mathrm{t})] \mathrm{dt}-\int_{\mathrm{a}}^{0} \mathrm{~V}^{\prime \prime}{ }_{w}(x) \int_{\mathrm{a}}^{\mathrm{x}}(\mathrm{G}(\mathrm{t})-\mathrm{F}(\mathrm{t})) \mathrm{dtd} \mathrm{x} \\
& +\mathrm{V}^{\prime}{ }_{w}(\mathrm{~b}) \int_{0}^{\mathrm{b}}(\mathrm{G}(\mathrm{t})-\mathrm{F}(\mathrm{t})) \mathrm{dt}-\int_{0}^{\mathrm{b}} \mathrm{V}^{\prime \prime}{ }_{w}(x) \int_{0}^{\mathrm{x}}(\mathrm{G}(\mathrm{t})-\mathrm{F}(\mathrm{t})) \mathrm{dtdx} .
\end{aligned}
$$

For $0<\mathrm{x} \leq \mathrm{b}, \mathrm{V}^{\prime \prime}{ }_{\mathrm{w}}(\mathrm{x}) \leq 0$; hence, if in this range $\int_{0}^{\mathrm{x}}(\mathrm{G}(\mathrm{t})-\mathrm{F}(\mathrm{t})) \mathrm{dt} \geq 0$ for all $\mathrm{x}$, then the last two terms on the right-hand side of eq. (11) will be non-negative (because $\mathrm{V}_{\mathrm{w}}{ }_{\mathrm{w}}(\mathrm{b}) \geq 0$ ). With regard to the range a $a \leq x<0, V^{\prime \prime}{ }_{w}(x) \geq 0$, it is tempting to require that in the range zero to $\mathrm{x}$ the integral $\int_{0}^{x}(G(t)-F(t)) d t \leq 0$ is negative, to insure that $\Delta \geq 0$. However, this would be an error because this condition does indeed, guarantee that the second term on the right-hand side of eq. (11) is non-negative. However, the first term on the right-hand side of eq. (11) may be negative, which does not guarantee that $\Delta \geq 0$. Therefore, for $\Delta$ to be non-negative, we have to rewrite the second term on the right-hand side of (11) as follows: 


$$
\begin{aligned}
& -\int_{\mathrm{a}}^{0} \mathrm{~V}_{w}(x) \int_{\mathrm{a}}^{\mathrm{x}}(\mathrm{G}(\mathrm{t})-\mathrm{F}(\mathrm{t})) \mathrm{dtd} \mathrm{x}= \\
& =-\int_{\mathrm{a}}^{0} \mathrm{~V}_{w}(x) \int_{\mathrm{a}}^{0}(\mathrm{G}(\mathrm{t})-\mathrm{F}(\mathrm{t})) \mathrm{dtdx}+\int_{\mathrm{a}}^{0} \mathrm{~V}^{\prime \prime}{ }_{w}(x) \int_{\mathrm{x}}^{0}(\mathrm{G}(\mathrm{t})-\mathrm{F}(\mathrm{t})) \mathrm{dtdx} .
\end{aligned}
$$

The first term on the right-hand side of eq. (12) can be rewritten as:

$$
\begin{aligned}
& -\int_{\mathrm{a}}^{0}(\mathrm{G}(\mathrm{t})-\mathrm{F}(\mathrm{t})) \mathrm{dt} \int_{\mathrm{a}}^{0} \mathrm{~V}^{\prime \prime}{ }_{w}(x) d x=-\left.\mathrm{V}^{\prime}{ }_{w}(x)\right|_{a} ^{0} \int_{\mathrm{a}}^{0}(\mathrm{G}(\mathrm{t})-\mathrm{F}(\mathrm{t})) \mathrm{dt} \\
& =-\mathrm{V}_{w}^{\prime}(0) \int_{\mathrm{a}}^{0}(\mathrm{G}(\mathrm{t})-\mathrm{F}(\mathrm{t})) \mathrm{dt}+\mathrm{V}^{\prime}{ }_{w}(\mathrm{a}) \int_{\mathrm{a}}^{0}(\mathrm{G}(\mathrm{t})-\mathrm{F}(\mathrm{t})) \mathrm{dt} .
\end{aligned}
$$

Thus, eq. (12) takes the form:

$$
\begin{aligned}
& -\int_{\mathrm{a}}^{0} \mathrm{~V}^{\prime \prime}(x) \int_{\mathrm{a}}^{\mathrm{x}}(\mathrm{G}(\mathrm{t})-\mathrm{F}(\mathrm{t})) \mathrm{dtdx}=-\mathrm{V}^{\prime \prime}(0) \int_{\mathrm{a}}^{0}(\mathrm{G}(\mathrm{t})-\mathrm{F}(\mathrm{t})) \mathrm{dt} \\
& +\mathrm{V}^{\prime}{ }_{w}(\mathrm{a}) \int_{\mathrm{a}}^{0}(\mathrm{G}(\mathrm{t})-\mathrm{F}(\mathrm{t})) \mathrm{dt}+\int_{\mathrm{a}}^{0} \mathrm{~V}^{\prime \prime}{ }_{w}(x) \int_{\mathrm{x}}^{0}(\mathrm{G}(\mathrm{t})-\mathrm{F}(\mathrm{t})) \mathrm{dtdx},
\end{aligned}
$$

which leads to the following expression for $\Delta$ :

$$
\begin{aligned}
& \Delta=\mathrm{V}^{\prime}{ }_{w}(\mathrm{a}) \int_{\mathrm{a}}^{0}(\mathrm{G}(\mathrm{t})-\mathrm{F}(\mathrm{t})) \mathrm{dt}+\int_{\mathrm{a}}^{0} \mathrm{~V}^{\prime \prime}{ }_{w}(x) \int_{\mathrm{x}}^{0}(\mathrm{G}(\mathrm{t})-\mathrm{F}(\mathrm{t})) \mathrm{dtdx} \\
& +\mathrm{V}^{\prime}{ }_{w}(\mathrm{~b}) \int_{0}^{\mathrm{b}}(\mathrm{G}(\mathrm{t})-\mathrm{F}(\mathrm{t})) \mathrm{dt}-\int_{0}^{\mathrm{b}} \mathrm{V}^{\prime \prime}{ }_{w}(x) \int_{0}^{\mathrm{x}}(\mathrm{G}(\mathrm{t})-\mathrm{F}(\mathrm{t})) \mathrm{dtdx} .
\end{aligned}
$$

From eq. (14) we can see that if

$$
\int_{x}^{0}(G(t)-F(t)) d t \geq 0 \text { for all } x \leq 0
$$


and

$$
\int_{0}^{x}(G(t)-F(t)) d t \geq 0 \text { for all } x \geq 0
$$

then, because $\mathrm{V}^{\prime}{ }_{\mathrm{w}}(\mathrm{x}) \leq 0$ for $\mathrm{x}>0$ and $\mathrm{V}^{\prime}{ }_{\mathrm{w}}(\mathrm{x}) \geq 0$ for $\mathrm{x}<0$ and $\mathrm{V}^{\prime}{ }_{\mathrm{w}}(\mathrm{b}) \geq 0, \mathrm{~V}_{\mathrm{w}}^{\prime}(\mathrm{a}) \geq 0$, we obtain $\Delta \geq 0$, namely, $\mathrm{F}$ dominates $\mathrm{G}$ by PSD, or F dominates $\mathrm{G}$ for all $\mathrm{S}$-shaped value functions. To complete the sufficiency side of the proof, we need to show that there exists an S-shaped value function for which the difference $\Delta$ is positive. This is simple and we omit it.

Conditions (15) and (16) are equivalent to the condition:

$$
\int_{y}^{x}(G(t)-F(t)) d t \geq 0 \text { for any pair of } x \text { and } y \text { such that } y<0<x \text {, Q.E.D. }
$$

b) Necessity. To prove necessity, we have to show that if for every S-shaped value function a prospect $\mathrm{F}$ is better than prospect $\mathrm{G}$, then for every $\mathrm{y}<0<\mathrm{x}$,

$$
\int_{y}^{x}(G(t)-F(t)) d t \geq 0
$$

We prove this by contradiction. Assume that for every S-shaped function, F is preferred but there exists a pair of values $\left(\mathrm{x}_{0}, \mathrm{y}_{0}\right)$, for which the above integral is negative and $\mathrm{y}_{0}<0<\mathrm{x}_{0}$. We show this with the following S-shaped function (see Figure 7).

$$
\mathrm{V}_{\mathrm{w}}(t)=\left\{\begin{array}{l}
x_{0}, \text { when } x_{0} \leq t \\
t, \quad \text { when } y_{0}<t<x_{0} \\
y_{0}, \text { when } t \leq y_{0}
\end{array}\right.
$$

(Insert Figure 7 here)

Because, by assumption, $\mathrm{F}$ is preferred over $\mathrm{G}$ for all S-shaped functions, for our specific utility function we have $\mathrm{E}_{\mathrm{F}}\left(\mathrm{V}_{\mathrm{w}}(\mathrm{t})\right) \geq \mathrm{E}_{\mathrm{G}}\left(\mathrm{V}_{\mathrm{w}}(\mathrm{t})\right)$ which means: 


$$
\Delta=\int_{a}^{b} \mathrm{~V}_{\mathrm{w}}(t) d F-\int_{a}^{b} \mathrm{~V}_{\mathrm{w}}(t) d G=\left.\left(\mathrm{V}_{\mathrm{w}}(t) F(t)-\mathrm{V}_{\mathrm{w}}(t) G(t)\right)\right|_{a} ^{b}-\int_{a}^{b} \mathrm{~V}_{\mathrm{w}}^{\prime}(t)(F(t)-G(t)) d t \geq 0
$$

Because $\mathrm{F}(\mathrm{a})=\mathrm{G}(\mathrm{a})=0$ and $\mathrm{F}(\mathrm{b})=\mathrm{G}(\mathrm{b})=1$ (because $\mathrm{F}$ and $\mathrm{G}$ are cumulate distribution functions), and using the fact that $\mathrm{V}_{\mathrm{w}}^{\prime}$ is zero below $\mathrm{y}_{0}$ and above $\mathrm{x}_{0}$, the previous expression can be written as:

$$
\Delta=\int_{\mathrm{a}}^{\mathrm{b}} \mathrm{V}_{w}^{\prime}(t)(G(t)-F(t)) d t=\int_{\mathrm{x}_{0}}^{\mathrm{y}_{0}}(G(t)-F(t)) d t \geq 0,
$$

which contradicts the assumption that the integral is negative for all pairs $\mathrm{x}, \mathrm{y}$ such that $\mathrm{y}<0<\mathrm{x}$.

Corollary. F dominates G by PSD if and only if F dominates G for all path-dependent utility functions $\mathrm{U}(\mathrm{w}, \mathrm{x})$ given by eq. (1).

The proof is straightforward. To see this, note that because $\mathrm{U}(\mathrm{w}, \mathrm{x})=\mathrm{U}(\mathrm{w})+\mathrm{V}_{\mathrm{w}}(\mathrm{x})$ and $\mathrm{U}^{\prime}(\mathrm{w}, \mathrm{x})=\mathrm{V}^{\prime}{ }_{\mathrm{w}}(\mathrm{x}), \mathrm{U}^{\prime \prime}(\mathrm{w}, \mathrm{x})=\mathrm{V}^{\prime \prime}{ }_{\mathrm{w}}(\mathrm{x})$, (all derivations are with respect to $\left.\mathrm{x}\right)$. Thus, the PSD proof with $\mathrm{U}(\mathrm{w}, \mathrm{x})$ is the same as in Theorem 2 : simply substitute $\mathrm{U}$ for $\mathrm{V}_{\mathrm{w}}$ everywhere.

\section{A. Discussion}

In expected utility theory, the main parameter is total wealth $\mathrm{w}+\mathrm{x}$ and not change in wealth, $\mathrm{x}$, which is the main parameter in prospect theory. Thus, it would seem that the results of Theorem 2 do not apply to utility theory. However this is not the case, and the results of Theorem 2 hold for all S-shaped value functions $V_{w}(x)$ as well as for all NM utility functions of the form $U(w+x)$ such that $\mathrm{U}^{\prime \prime}(0)$ for all $\mathrm{x}<0$ and $\mathrm{U}^{\prime \prime}<0$ for $\mathrm{x}>0$. $\mathrm{U}^{\prime \prime}$ is a function of $\mathrm{w}$ just as $\mathrm{V}_{\mathrm{w}}{ }_{\mathrm{w}}(\mathrm{x})$ depends on w. Similarly, in utility theory, $\mathrm{F}$ and $\mathrm{G}$ should be defined on terminal wealth $\mathrm{w}+\mathrm{x}$ and not on $\mathrm{x}$ as shown in the proof of Theorem 2. However, because 


$$
\int_{y}^{x}(G(t)-F(t)) d t>0 \Leftrightarrow \int_{y-w}^{x-w}(G(w+t)-F(w+t)) d t>0
$$

w can be ignored. From these two properties we can conclude the following:

Theorem 3. F dominates G by prospect theory (PSD) for all S-shaped value functions, if and only if $\mathrm{F}$ dominates $\mathrm{G}$ in the expected utility framework for all S-shaped utility functions of the form $\mathrm{U}(\mathrm{w}+\mathrm{x})$ and $\mathrm{U}^{\prime \prime}(\mathrm{w}+\mathrm{x}) \geq 0$ for $\mathrm{x}<0$ and $\mathrm{U}^{\prime \prime}(\mathrm{w}+\mathrm{x}) \leq 0$ for $\mathrm{x}>0$ and $\mathrm{U}^{\prime}>0$.

The proof is simple: In Theorem 2 substitute, $\mathrm{U}(\mathrm{w}+\mathrm{x})$ for $\mathrm{V}_{\mathrm{w}}(\mathrm{x})$ and $\mathrm{F}(\mathrm{w}+\mathrm{x})$ and $\mathrm{G}(\mathrm{w}+\mathrm{x})$ for $\mathrm{F}(\mathrm{x})$ and $\mathrm{G}(\mathrm{x})$, respectively.

Thus, PSD with the value function $V_{w}$ can be viewed as a special case of expected utility with an S-shaped utility function whose inflection point is at current wealth w, with risk seeking for $\mathrm{x}<0$ and risk aversion for $\mathrm{x}>0$.

Example: Suppose that we have the following two alternative prospects, $F$ and $G$ :

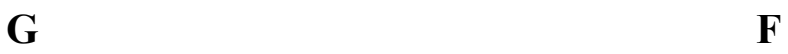

$\begin{array}{cccc}\text { Outcome } & \text { Probability } & \text { Outcome } & \text { Probability } \\ -5 & 1 / 2 & -10 & 1 / 4 \\ 0 & 1 / 4 & 0 & 1 / 4 \\ 25 & 1 / 4 & +10 & 1 / 4 \\ & & +20 & 1 / 4\end{array}$

Figure 8 illustrates the cumulative distributions $\mathrm{F}$ and $\mathrm{G}$

(Insert Figure 8 here)

As can be seen from this example, neither F nor G dominates the other by FSD (because the two cumulative distributions intersect). Yet there is a PSD of F over G (for all S-shaped value functions and for all S-shaped utility functions). To see this, note that 
$\int_{x}^{0}(G(t)-F(t)) d t \geq 0$ for all $x \leq 0$, and $\int_{0}^{x}(G(t)-F(t)) d t \geq 0$ for all $x \geq 0$ (and there is at least one strict inequality). Alternatively, for any pair $y \leq 0, x \geq 0$, the integral $\int_{y}^{x}(G(t)-F(t)) d t \geq 0$ is positive implying that $\mathrm{F}$ dominates $\mathrm{G}$ by PSD.

It is interesting to note that in the above example, neither F nor $\mathrm{G}$ dominates the other by second degree stochastic dominance (SSD), because F dominates G by SSD if and only if:

$$
\int_{a}^{x}(G(t)-F(t)) d t>0
$$

for all values $\mathrm{x}$ (with at least one strict inequality). This condition does not hold for $\mathrm{x}<-5$. Hence, $\mathrm{F}$ does not dominate $\mathrm{G}$ by SSD. It is easy to show that $\mathrm{G}$ also does not dominate $\mathrm{F}$ by $\operatorname{SSD}\left(\right.$ for $x=10$, the integral is negative: $\left.\int_{a}^{10}(F(t)-G(t)) d t<0\right)$.

Finally, if $\mathrm{F}$ dominates $\mathrm{G}$ by FSD, it implies that $\mathrm{F}$ dominates $\mathrm{G}$ by PSD. To see this, recall that FSD dominance implies that,

$$
\mathrm{F}(\mathrm{w}+\mathrm{x}) \leq \mathrm{G}(\mathrm{w}+\mathrm{x}) \text { for all } \mathrm{x}
$$

which is the same as $F(x) \leq G(x)$ for all $x$. However, because $V^{\prime \prime}(x) \geq 0$, from equation (10), it is obvious that if $\mathrm{F}$ dominates $\mathrm{G}$ by $\mathrm{FSD}, \Delta \geq 0$ for all value functions $\mathrm{V}_{\mathrm{w}}$ with $\mathrm{V}^{\prime}{ }_{\mathrm{w}}(\cdot) \geq 0$; hence $\mathrm{F}$ dominates G by PSD. It is easy to show that SSD, unlike FSD, does not imply PSD.

\section{B. Weight Function}

In proving $\mathrm{PSD}$, we assume that $\mathrm{F}$ and $\mathrm{G}$ are the original distributions and no transformation on the probabilities is made. However, if a transformation on the cumulative distributions is made (as advocated by CPT, in Tversky and Kahneman (1992), with $\mathrm{F}^{*}=\mathrm{T}(\mathrm{F})$ 
and $\mathrm{G}^{*}=\mathrm{T}(\mathrm{G})$, $\mathrm{T}$ being a monotonous non-decreasing transformation used by all investors), then PSD will hold but, this time, the condition will be $\int_{x}^{y}\left(G^{*}(t)-F^{*}(t)\right) d t=0$ for all $y<0$ and $x>0$.

\section{Conclusions}

Most equilibrium models and criteria for decision making under uncertainty (e.g., equilibrium prices of risky assets, portfolio theory, risk premium and stochastic dominance rules) were developed within the expected utility paradigm. Markowitz (1952) and Allais (1953) suggested that investors do not make choices in accordance to EU. Moreover, experiments conducted with and without real money show that subjects violate the expected utility paradigm and, in particular, the independence axiom. Following Markowitz (1952) and Edwards (1953, 1954), Kahneman and Tversky's (1979). Prospect Theory shows that a high proportion of subjects maximize their expected value function, $\mathrm{V}_{\mathrm{w}}(\mathrm{x})$, where $\mathrm{x}$ is the unexpected change in wealth (gains or losses) rather than total wealth. This runs counter to the assertion of expected utility that investors maximize the expected value of the function $U(w+x)$, where $w^{+} x$ is the total wealth.

In this paper, we bridge the gap between prospect theory and expected utility theory. We first define a two-dimensional utility function $\mathrm{U}(\mathrm{w}, \mathrm{x})$ and show that investors make decisions according to these two variables, exactly as claimed by prospect theory. In comparison to NM utility function $\mathrm{U}(\mathrm{w}, \mathrm{x})$ is a path-dependent: ending up with a wealth $\mathrm{w}+\mathrm{x}$ may provide in the short run a different utility, depending on the path by which $w^{+}+x$ was achieved. The function $\mathrm{U}(\mathrm{w}, \mathrm{x})$ is also time-dependent because the utility may change with time. Hence $\mathrm{U}(\mathrm{w}, \mathrm{x})$ is pathtime dependent utility function. This function reflects the Temporary Attitude Towards Risk (TATR). If one observes a continuous process of gain accumulation or wealth loss, then the 
behavior will be according to the one-dimensional utility function. However, when the change in wealth $\mathrm{x}$ is sudden and unexpected (e.g. October 1987 or September 2001 crashes) then the psychological effects come to play and investors act according to the two dimensional utility function $\mathrm{U}(\mathrm{w}, \mathrm{x})$, i.e. according to Markowitz or Kahneman and Tversky's PT utility (or value) functions. When the subjects adjust to the gain or loss, there is a shift from the function $U(w, x)$ to the $\mathrm{NM}$ utility function $\mathrm{U}(\mathrm{w}+\mathrm{x})$, and the utility function $\mathrm{U}(\mathrm{w}+\mathrm{x})$ reflects the Permanent Attitude Towards Risk (PATR). This two-dimensional utility function together with the conventional NM utility function $\mathrm{U}(\mathrm{w}+\mathrm{x})$ can explain Thaler and Johnson's (1990) experimental results as well as short-run stock price overreaction to unexpected bad or good news. Because investors make decisions based on a change in wealth rather then terminal wealth, these decisions are myopic and often not optimal. In the long run investors return to the NM expected utility framework. Behavioral mutual funds can make abnormal profits due to these errors.

Next we analyze the impact of the empirically found positive risk premium and a decreasing absolute risk aversion on the shape of the value function advocated by prospect theory. We find that positive risk premium is consistent with Kahneman and Tversky's value function (as well as with Markowitz utility function) indicating that the convex part of the value function is steeper than the concave part, and decreasing risk premium under certain conditions implies that the value function shifts in a clockwise direction as wealth increases.

According to prospect theory, the value function by which investors make investment decisions is an S-shaped function that varies from one investor to another, depending on his/her preference and their wealth, but preserves its S-shape. Moreover, the value function of the same investor may not be the same for different levels of hypothetical wealth. In the final part of this study, we develop an investment decision rule called Prospect Stochastic Dominance (PSD) deriving the conditions under which one prospect $\mathrm{x}$ will dominate another prospect $\mathrm{y}$ for all $\mathrm{S}$ - 
shaped Kahneman and Tversky value functions. We show that PSD holds if and only if such dominance holds for the path-dependent utility function $\mathrm{U}(\mathrm{w}, \mathrm{x})$ as well as for the NM utility function $\mathrm{U}(\mathrm{w}+\mathrm{x})$, which is also S-shaped with a reference point $\mathrm{w}$. We also show that First Degree Stochastic Dominance (FSD) implies PSD but not vice versa. 


\section{REFERENCES}

Allais, M. "Le comportement de l'homme rationnel devant le risque: Critique des postulates et axioms de l'ecole Americaine", Econometrica, 21 (1953), 503-546.

Allais, M. "The General Theory of Random Choices in Relation to the Invariant Cardinal Utility Function and the Specific Probability Function. The $(U, \Theta)$ Model. A General Overview”, in B. Munier (ed.) Risk, Decision and Rationality, (Dordrecht, Reidel), (1988), 231-289.

Allais, M. "Allais Paradox", in The New Palgrave: Utility and Probability, The Macmillan Press, (1990), 3-9.

Arrow, K. Aspects of the Theory of Risk-Bearing, Helsinki, Yrjö Jahnssonin Säätiö, (1965).

Barberis, N., Huang, M. Santos, T. "Prospect Theory and Asset Prices", The Quarterly Journal of Economics, 116:1 (2001), 1-53.

Benartzi, S. and Thaler, R. "Myopic Loss Aversion and the Equity Premium Puzzle", The Quarterly Journal of Economics, 110:1 (1995), 73-92.

Conrad, J. and Gautam K., “Long-Term Market Overreaction or Biases in Computed Returns?”, Journal of Finance, 48:1 (1993), 39-63.

Conrad, J. and Gautam K., "Mean Reversion in Short-Horizon Expected Returns", Review of Financial Studies, 2:2 (1989), 225-240.

De Bondt, W. and Thaler, R. "Does the stock market overreact?", Journal of Finance, 42:3 (1985), 793-808.

De Bondt, W. and Thaler, R. "Further evidence on investor overreaction and stock market seasonability", Journal of Finance, $42: 3$ (1987), 557-581.

Edwards, W. "Probability-preferences in gambling", American Journal of Psychology, 66 (1953), 349-364.

Edwards, W. "Probability-preferences among bets with differing expected values", American 
Journal of Psychology, 67 (1954), 56-67.

Friedman, M. and Savage, L. "The Utility Analysis of Choices Involving Risk", Journal of Political Economy, 56:4 (1948), 279-304.

Hanoch, G. and Levy, H. "The Efficiency Analysis of Choices Involving Risk", Review of Economic Studies, 36:107 (1969), 335-346.

Handa, J. "Risk, Probabilities, and a New Theory of Cardinal Utility", Journal of Political Economy, 85:1 (1977), 97-122.

Ibbotson Associates, Stocks, Bonds, Bills and Inflation, Chicago, various issues.

Kahneman, D. and Tversky, A. "Prospect Theory of Decisions Under Risk", Econometrica, 47:2 (1979), 263-291.

Kihlstrom, R. and Mirman, L. "Risk Aversion with Many Commodities", Journal of Economic Theory 8:3 (1974), 361-388.

Kihlstrom, R. and Mirman, L. "Constant Increasing and Decreasing Risk Aversion with Many Commodities”, Review of Economic Studies, 48:2 (1981), 271-280.

Lehmann, B. "Fads, Martingales and Market Efficiency", Quarterly Journal of Economics, 105 (1990), 1-28.

Levhari, D., Paroush, J. and Peleg, B. "Efficiency Analysis for Multivariate Distributions", Review of Economic Studies, 42:1 (1975), 87-91.

Levy, H. "Multi-period Consumption Decisions Under Conditions of Uncertainty", Management Science, 22:11 (1976), 1258-1267.

Levy, H. “Stochastic Dominance: Survey and Analyses”, Management Science, 38:4 (1992), 555-593.

Levy, H. "Absolute and Relative Risk Aversion: An Experimental Study", Journal of Risk and Uncertainty, 8 (1994), 289-302. 
Levy, H. and Paroush, J. "Toward Multivariate Efficiency Criteria", Journal of Economic Theory, 7 (1974), 129-142.

Levy, H. and Wiener, Z. "Stochastic Dominance and Prospect Dominance with Subjective Weighting Functions", Journal of Risk and Uncertainty, 16 (1998), 147-164.

Lo, A. and Mackinlay, C. "Stock Market Prices Do Not Follow Random Walks: Evidence from a Simple Specification Test”, Review of Financial Studies, 1 (1988), 41-66.

Markowitz, H., “The Utility of Wealth”, Journal of Political Economy, 60 (1952), 151-156.

March, J. and Shapira, Z. "Variable Risk Preferences and the Focus of Attention", Psychological Review, 99:1 (1992), 172-183.

Machina, M. "Choice Under Uncertainty: Problems Solved and Unsolved", Economic Perspectives, 1:1 (1987), 121-154.

Mosteller, F. and Nogee, P. "An experimental measurement of utility”, Journal of Political Economy, 59 (1951), 371-404.

Pratt, J. "Risk Aversion in the Small and in the Large", Econometrica, 32:1-2 (1964), 122-136.

Samuelson, W., and Zeckhauser, R. "Status Quo Bias in Decision Making", Journal of Risk and Uncertainty, 1 (1988), 7-59.

Rabin, M. "Psychology and Economics", Journal of Economic Literature, 36 (1998), 11-46.

Shefrin, H., and M. Statman. "Behavioral Portfolio Theory", Journal of Financial and Quantitative Analysis, 35:2 (2000), 127-151.

Shefrin, H., and Statman, M. "The Disposition to Sell Winners Too Early and Ride Losers Too Long: Theory and Evidence", The Journal of Finance, 41:3 (1985), 777-782.

Starmer, C. "Developments in Non-Expected Utility Theory: The Hunt for a Descriptive Theory of Chioce under Risk", Journal of Economic Literature, 38 (2000), 332-382.

Thaler, R. and Johnson, E. "Gambling with the House Money and Trying to Break Even: the 
Effects of Prior Outcomes on Risky Choice”, Management Science, 36:3 (1990), 643-660.

Tversky, A. and Kahneman, D. "Advances in Prospect Theory: Cumulative Representation of Uncertainty”, Journal of Risk and Uncertainty, 5 (1992), 297-323.

Tversky, A. and Wakker, P. "Risk Attitudes and Decision Weights", Econometrica, 63:6 (1995), $1255-1280$.

Varey, C. and Kahneman, D. "Experiences Extended Over Time: Evaluation of Moments and Episodes", Journal of Behavioral Decision Making, 5 (1992), 169-185.

Quiggin, J. "A Theory of Anticipated Utility”, Journal of Economic Behavior and Organization, 3 (1982), 323-343.

Quiggin, J. "Decision Weights in Anticipated Utility Theory: Response", Journal of Economic Behavior and Organization, 8:4 (1987), 641-45.

Yaari, M. “The Dual Theory of Choice Under Risk”, Econometrica, 55:1 (1987), 95-115. 


\section{Footnotes}

An attempt to combine Prospect Theory and market forces is made in Barberis, Huang, and Santos (1999). Various methods of distortion of probabilities are described in Edwards (1953, 1954) and Handa (1977). Distortion of cumulative probabilities is described in Quiggin (1982, 1987) and Yaari (1987). Levy and Wiener (1998) analyze the effect of various transformations on FSD as well as other stochastic dominance rules. For stochastic dominance rules see Levy (1992).

2 The function $\mathrm{U}(\mathrm{w})$ in the right-hand side is the standard $\mathrm{NM}$ utility and the $\mathrm{V}_{\mathrm{w}}(\mathrm{x})$ part represents the temporarily shift from the long-term utility caused by the recent gains/losses.

3 It is difficult to obtain precise information about the time needed for investors to adjust to their new wealth and to consider the sum of the old wealth and its change as their new endowment. However, based on results of Lo and MacKinley (1988) and Conrad and Kaul (1989), we conclude that this period is approximately 1-2 weeks. See also footnote 7.

$4 \quad$ See Machina (1987), Benartzi and Thaler (1995) and Starmer (2000) for excellent reviews of PT and myopic behavior.

5 Some studies claim that there are two reference points, see Samuelson and Zeckhauser (1988), March and Shapira (1992), Varey and Kahneman (1992).

6 Friedman and Savage (1948) and Markowitz (1952) suggest an explanation for the combination of risk seeking and risk aversion using NM utility function $\mathrm{U}(\mathrm{w})$.

7 See, for example, De Bondt and Thaler (1985, 1987), Lehmann (1990), Shefrin and Statman (1985) and Conard and Kaul (1993). Some studies claim that long-term overreaction 
also exists, but Conard and Kaul (1993) show that the overreaction disappears when various biases are corrected.

$8 \quad$ See Gene Epstein, “Efficient Market Humbug”, Barron’s, February 1, 1999, p. 44.

9 See Ibbotson Associate, “Stocks, Bonds, Bills and Inflation,” Chicago, 1999 yearbook.

10 Levy (1994), in an experimental study, (with real money gains and losses), finds decreasing absolute risk aversion.

11 Tversky and Wakker (1995) introduced the notion of sub-additivity (SA), and show that the relation "more-SA-than" between the weighting functions of different individuals is analogous to the Arrow-Pratt analysis of "more risk averse than". In this paper, we do not deal with the weighting functions but focus on value function and expected utility.

12 Note that Markowitz (1952) claims that the utility function is a reversed S-shaped with risk-seeking part for $\mathrm{x}>0$ and risk averse for $\mathrm{x}<0$ (see also Mosteller and Nogee (1951)). However, he also claims that the segment corresponding to $\mathrm{x}<0$ is steeper than the segment $\mathrm{x}>0$. We use in the proof only that $\beta>\alpha$, thus the same proof also works for the reversed S-shaped function as long as $\beta>\alpha$. In the case when $\beta=\alpha$, a similar result is obtained involving secondorder derivatives of the value function. However, the case $\beta>\alpha$ is the most important one, as noted in K\&T (1979).

13 Actually, $\beta>\alpha$ implies $\pi>0$, however, $\pi>0$ only implies that $\beta \geq \alpha$ because even when $\beta=\alpha$, higher derivatives can force $\pi$ to be positive.

$14 \quad$ We assume $\mathrm{E} \widetilde{\mathrm{X}} \neq 0$.

15

For the unbounded case, see Hanoch and Levy (1969). 


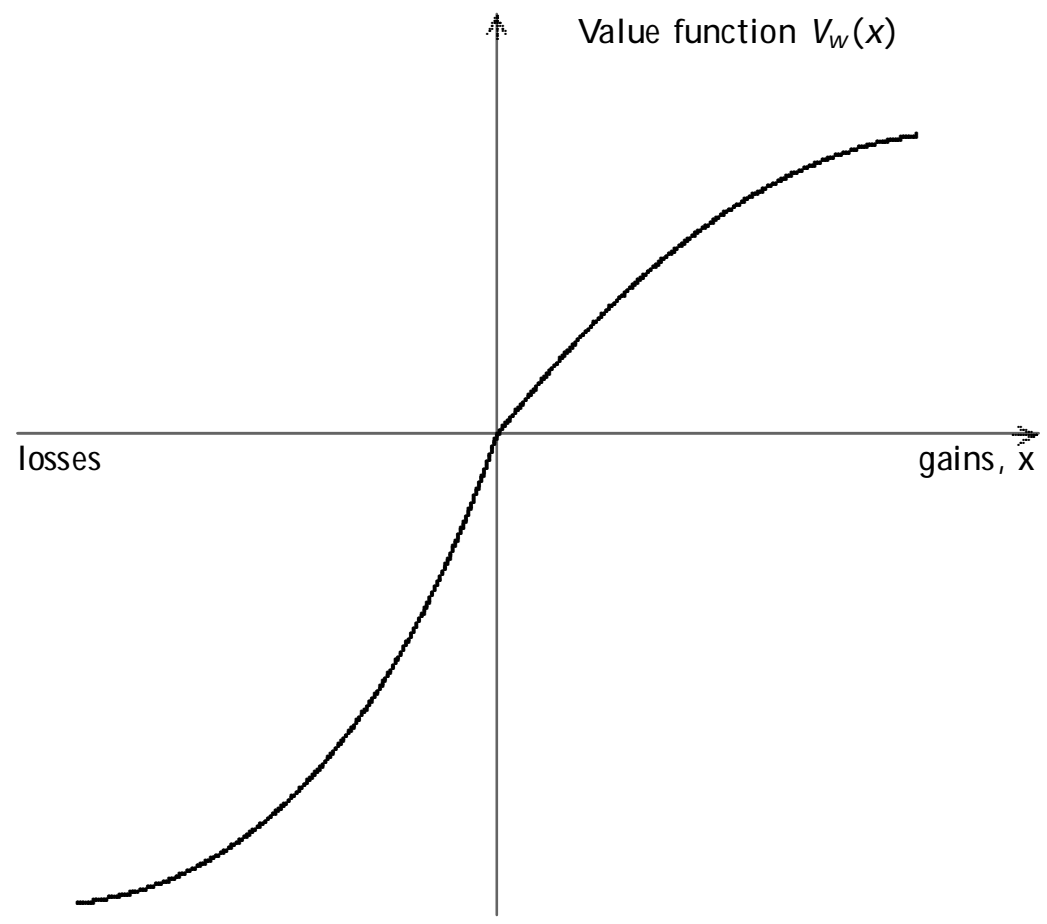

Figure 1a. A n example of an S-shaped value function.

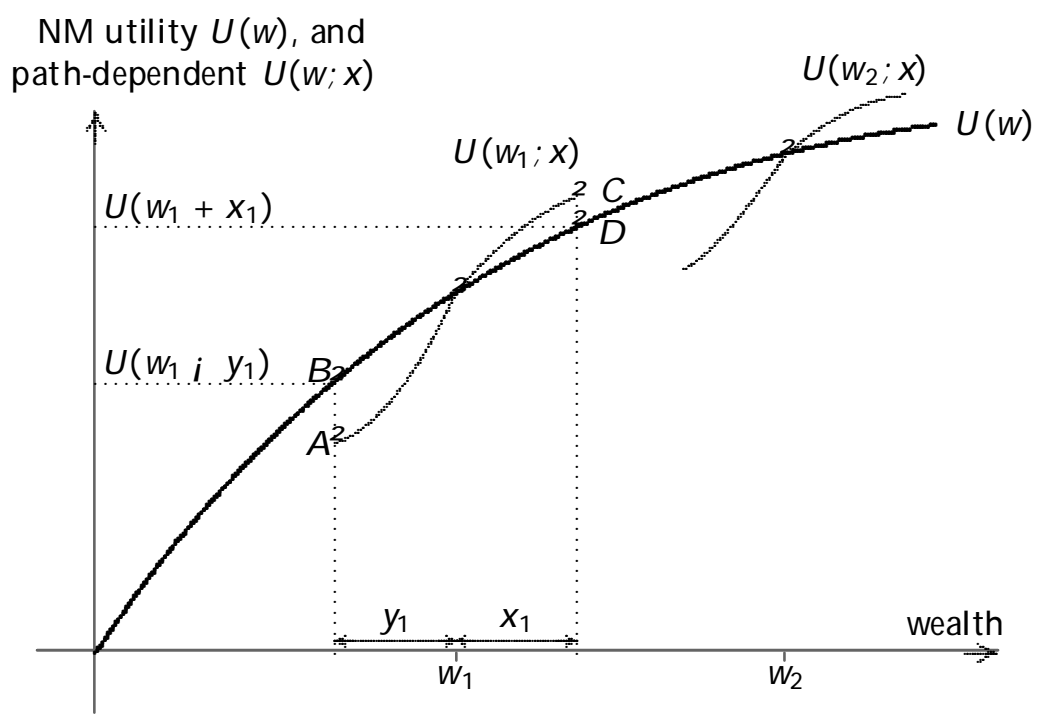

Figure 1b. Long-run NM utility function $U(w)$ (bold) and short-run path-dependent functions $U(w ; x)$. $A$ and $C$ indicate the points that in ${ }^{\circ}$ uence the decision, $B$ and $D$ correspond to utility after adjustment. 


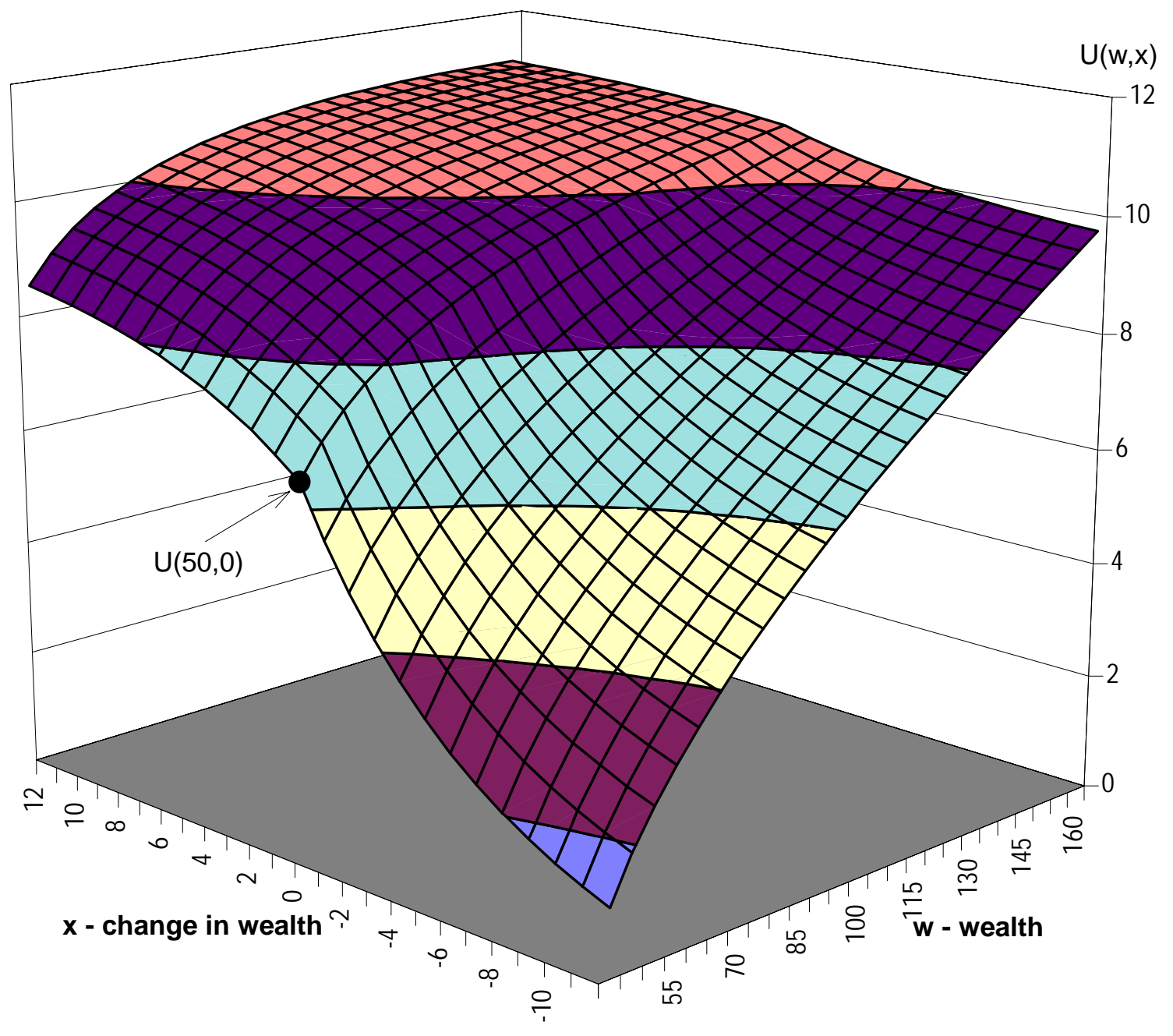

Figure 2. Two dimensional utility function depending on both wealth, $w$, and gain/loss, $\mathbf{x}$. For a given wealth, $w$, decisions are made according to the $S$-shaped section along the $x$-axis. After adjustments we return to the original utility function $(x=0)$. 


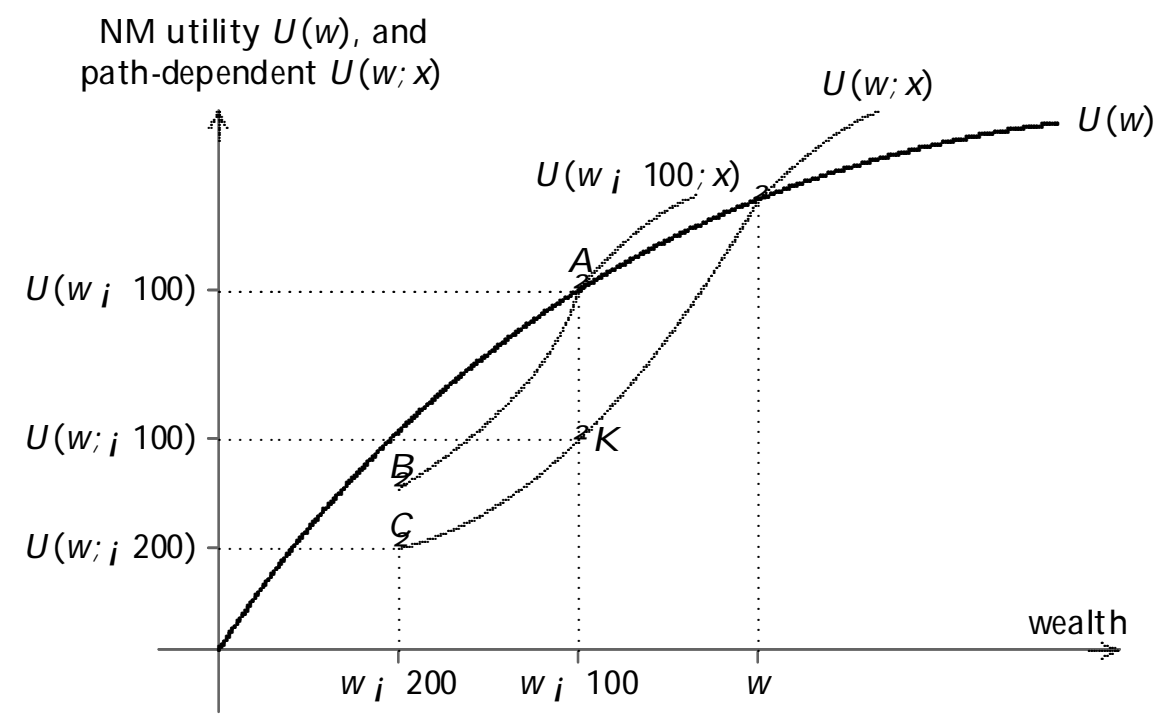

Figure 3. This - gure explains why a large loss may be worse than two smaller losses separated in time. 
NM utility $U(w)$, and

path-dependent $\mathrm{U}(\mathrm{w} ; \mathrm{x})$

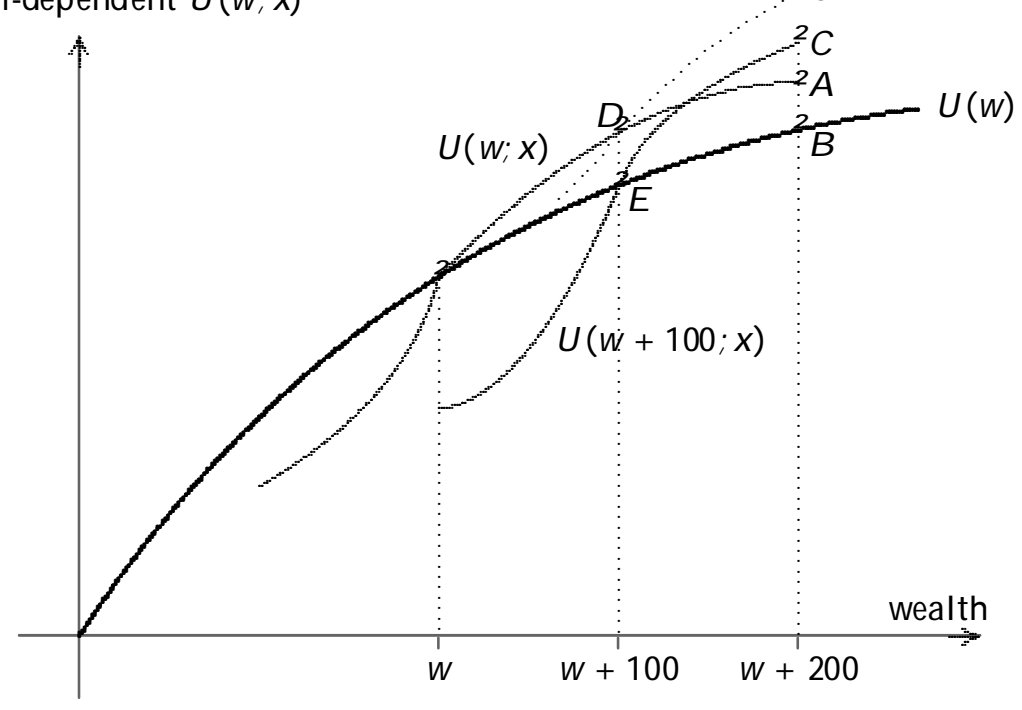

Figure 4. This - gure explains why two smaller gains separated in time may be better than a larger one-time gain. 


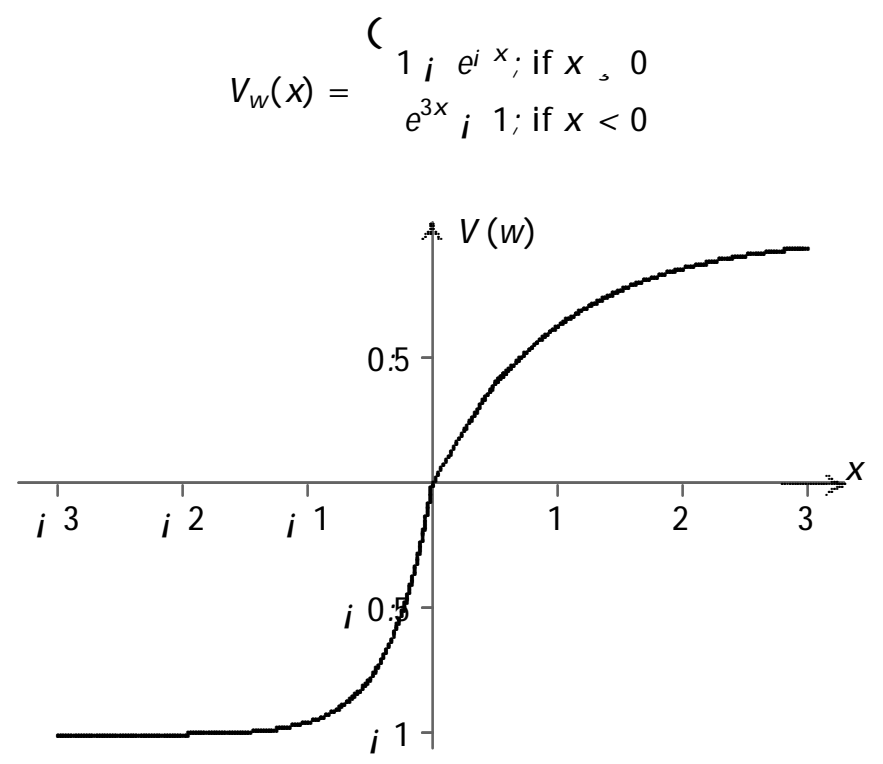

Figure 5a. Example of an S-shaped value function.

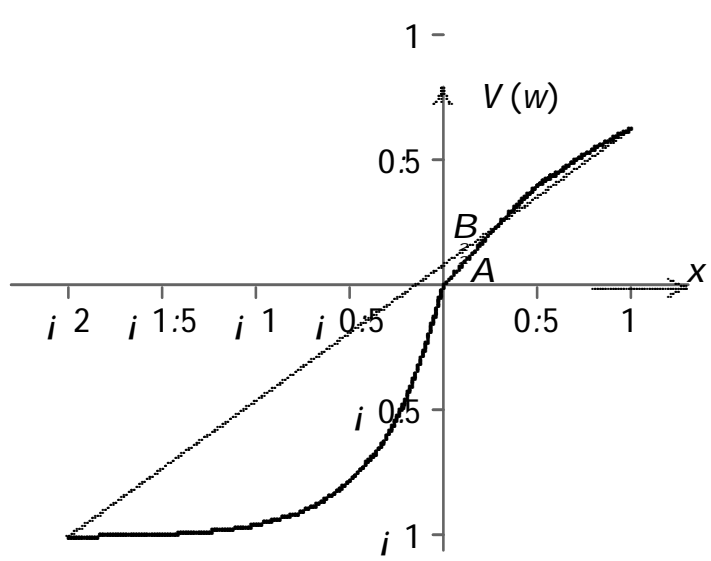

Figure 5b. Negative risk premium in the "Iarge." 


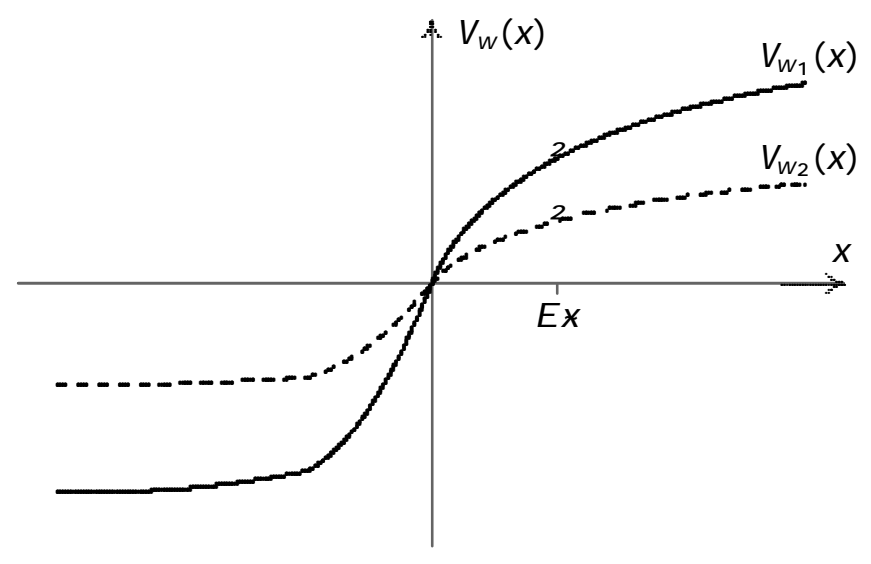

Figure 6a. Value function of the type $\mathrm{V}^{\mathrm{i}} \frac{\mathrm{x}}{\mathrm{w}}{ }^{\Phi}$ drawn for two values of wealth. Increasing wealth leads to clockwise rotation around the reference point.

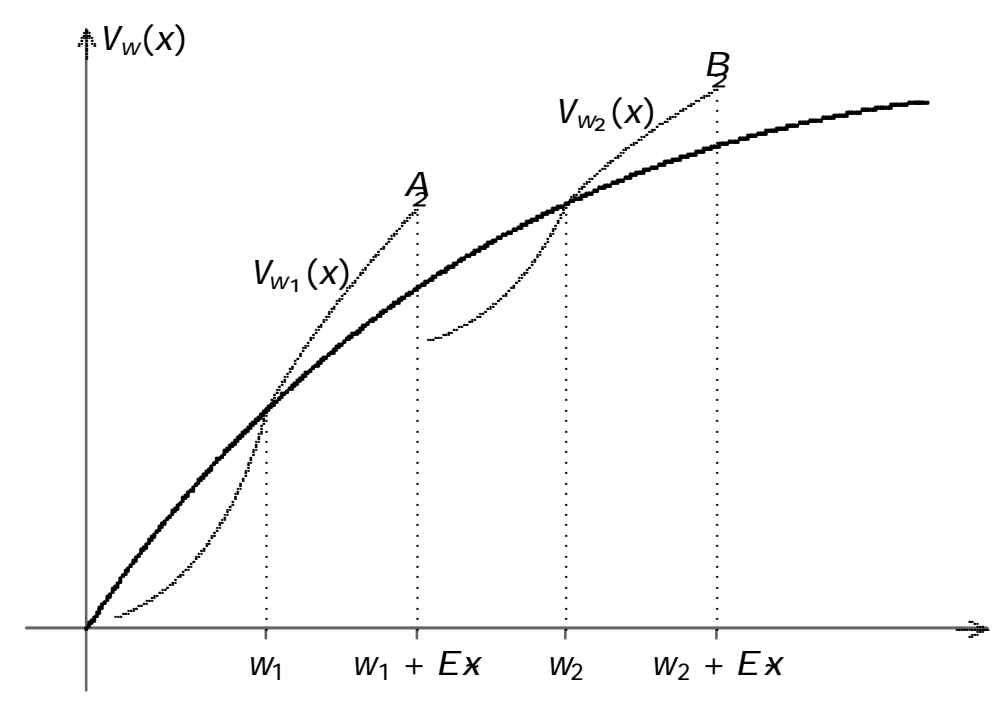

Figure 6b. Clockwise rotation with increase of wealth. 


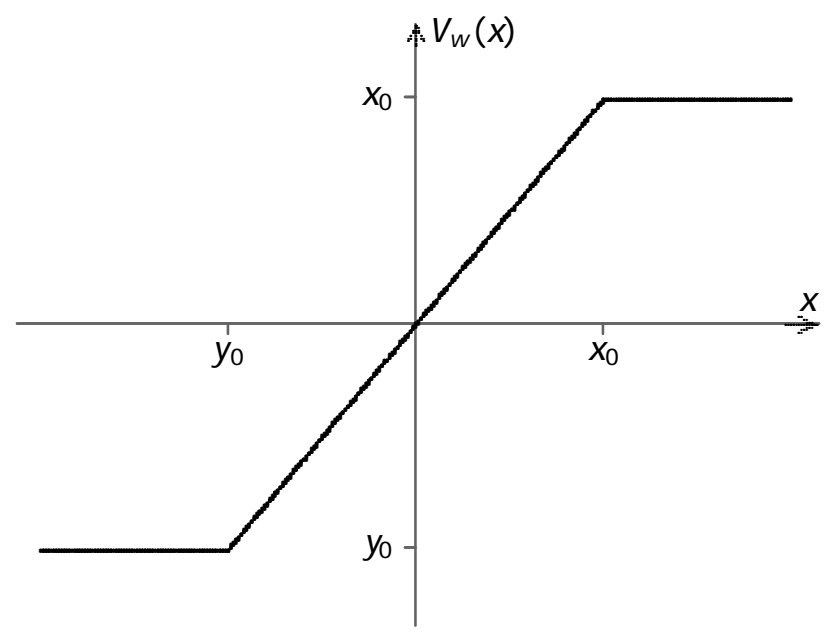

Figure 7. S-shaped test function for veri ${ }^{-}$cation of the necessity. 


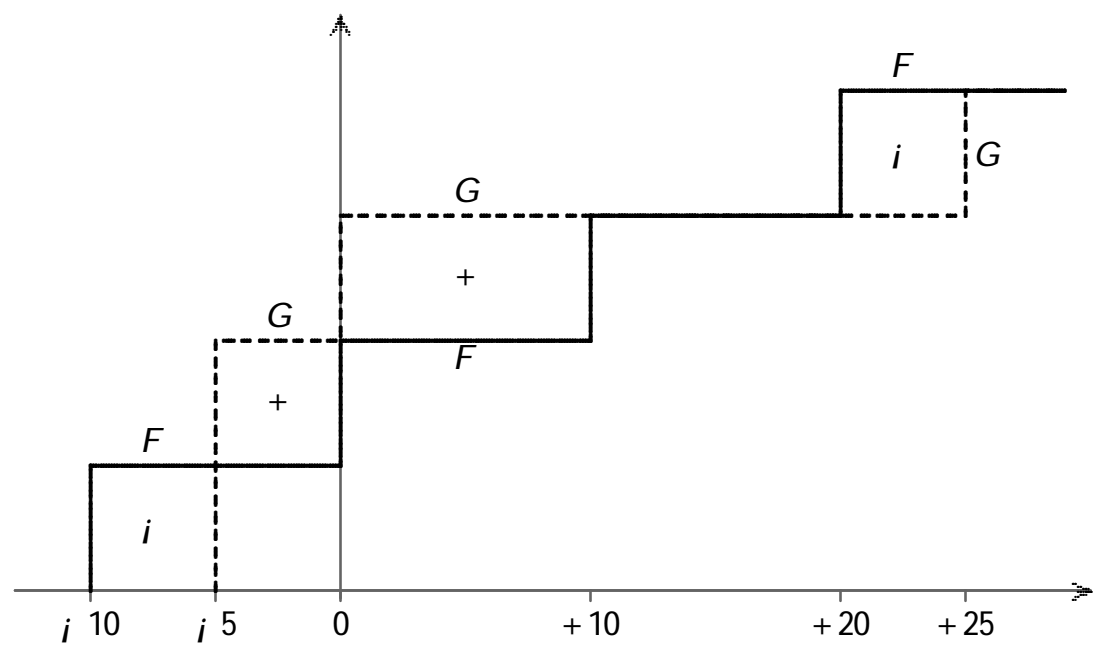

Figure 8. PSD in the absence of SSD. The solid line represents the cumulative payo ${ }^{\circledR}$ of $F$ and the dashed line, that of $G$. 